\title{
A Common Endocrine Signature Marks the Convergent Evolution of an Elaborate Dance Display in Frogs
}

\author{
Nigel K. Anderson, ${ }^{1}$ Eric R. Schuppe, ${ }^{2}$ K. V. Gururaja, ${ }^{3, \star}, \dagger$ Lisa A. Mangiamele, ${ }^{4, \star}$ Juan Carlos \\ Cusi Martinez, ${ }^{5, *}$ H. Priti, ${ }^{6, *}$ Rudolf von May, ${ }^{7, *}$ Doris Preininger, ${ }^{8}$ and Matthew J. Fuxjager ${ }^{1, \$}$ \\ 1. Department of Ecology, Evolution, and Organismal Biology, Brown University, Providence, Rhode Island 02906; 2. Department of \\ Neurobiology and Behavior, Cornell University, Ithaca, New York 14850; 3. Research and Development Center and Science Media Center, \\ Indian Institute of Science Campus, Gubbi Labs, Bengaluru, India 560012; 4. Department of Biological Sciences, Smith College, Northampton, \\ Massachusetts 01063; 5. Departamento de Herpetología, Museo de Historia Natural, Universidad Nacional Mayor de San Marcos, Avenida \\ Arenales 1256, Jesus Maria, Lima 14, Peru; 6. Centre for Ecological Sciences, Indian Institute of Science, Bangalore, India 560012; 7. Biology \\ Program, California State University Channel Islands, Camarillo, California 93012; 8. Vienna Zoo, 1130 Vienna, Austria; and Department of \\ Evolutionary Biology, University of Vienna, 1090 Vienna, Austria
}

Submitted May 13, 2020; Accepted May 4, 2021; Electronically published August 31, 2021

Dryad data: https://doi.org/10.5061/dryad.3n5tb2rhh.

AвSTRACт: Unrelated species often evolve similar phenotypic solutions to the same environmental problem, a phenomenon known as convergent evolution. But how do these common traits arise? We address this question from a physiological perspective by assessing how convergence of an elaborate gestural display in frogs (footflagging) is linked to changes in the androgenic hormone systems that underlie it. We show that the emergence of this rare display in unrelated anuran taxa is marked by a robust increase in the expression of androgen receptor (AR) messenger RNA in the musculature that actuates leg and foot movements, but we find no evidence of changes in the abundance of AR expression in these frogs' central nervous systems. Meanwhile, the magnitude of the evolutionary change in muscular AR and its association with the origin of foot-flagging differ among clades, suggesting that these variables evolve together in a mosaic fashion. Finally, while gestural displays do differ between species, variation in the complexity of a foot-flagging routine does not predict differences in muscular AR. Altogether, these findings suggest that androgen-muscle interactions provide a conduit for convergence in sexual display behavior, potentially providing a path of least resistance for the evolution of motor performance.

\footnotetext{
* Authors are listed alphabetically.

† Present address: School of Law, Environment and Planning, Srishti Institute of Art, Design and Technology, N4 Campus, CA Site 11, 5th Main, 5th Phase, Yelahanka New Town, Bengaluru, India 560064.

¥ Corresponding author; email: matthew_fuxjager@brown.edu.

ORCIDs: Anderson, http://orcid.org/0000-0003-2619-3405; Gururaja, http:// orcid.org/0000-0001-6907-9907; Priti, http://orcid.org/0000-0002-4526-139X; Mangiamele, http://orcid.org/0000-0003-4488-4904; Cusi Martinez, http:// orcid.org/0000-0002-1388-8024; von May, http://orcid.org/0000-0003-3981 -2615; Preininger, http://orcid.org/0000-0001-6842-1133; Fuxjager, http:// orcid.org/0000-0003-0591-6854.
}

Keywords: behavioral evolution, display design, androgen receptor, gestural signal, foot-flagging frogs.

\section{Introduction}

Animal life is replete with examples of convergent evolution, whereby similar traits independently emerge in different lineages to solve the same environmental problem (Morris 2003, 2008; Losos 2011). Many view convergence as strong evidence of phenotypic adaptation (Endler 1986; Harvey and Pagel 1991; Schluter 2000) and thus leverage the phenomenon as a natural experiment to study how fitness-enhancing traits can (or cannot) arise (Stewart et al. 1987; Losos 1992; West and Cohen 1996; Taylor and McPhail 2000; Kolbe et al. 2011; Mahler et al. 2013; Ord et al. 2013; Corcoran and Hristov 2014; Zhang et al. 2016; Young et al. 2019). A prime example is the research exploring the molecular and genetic bases of convergent evolution. This work has helped firmly establish our understanding of the role that genetic systems play in shaping trait adaptation (Chen et al. 1997; Yokoyama and Radlwimmer 2001; Wittkopp et al. 2003; Fry et al. 2009; Steiner et al. 2009; Li et al. 2010; Liu et al. 2010), including several highly complex traits, such as monogamy and subterranean living (Pascoal et al. 2014; Partha et al. 2017; Heyduk et al. 2019; Young et al. 2019). However, we remain unable to address many other important aspects of how convergence unfolds. For example, we know relatively little about its physiological basis (Fischer et al. 2019; Gallant and O'Connell 2020). Do similar traits arise in unrelated taxa via the same changes to the systems that "make organisms work," or might different 
species gain similar adaptations through different mechanistic modifications? These questions are particularly relevant to behavioral traits, which rely on coordination among many body systems (brain, muscles, hormones, etc.).

One physiological route by which selection can modify behavior is through the endocrine system. Hormones serve as messengers to coordinate the function of multiple body systems, and they regulate many fitness-related traits (AdkinsRegan 2005). Selection can drive the evolution of hormonesignaling systems largely by changing the underlying molecular pathways through which endocrine action occurs (King and Millar 1995; Denver 1999; Forsyth and Wallis 2002; Heyland et al. 2005). This phenomenon is perhaps best studied with regard to androgenic and estrogenic sex steroids (Hau 2007; Adkins-Regan 2008; Ketterson et al. 2009; McGlothlin et al. 2010; Fuxjager and Schuppe 2018; Cox 2020), which mediate the reproductive morphology and behavior of most vertebrates (Adkins-Reagan 2005). For example, adaptive shifts in sexual phenotype are often associated with changes in densities of sex steroid receptors (e.g., androgen receptor $[\mathrm{AR}]$ and estrogen receptor) at specific sites within the nervous and musculoskeletal systems (Canoine et al. 2007; Rosvall et al. 2012; Bergeon Burns et al. 2013; Fusani et al. 2014b; Fuxjager and Schlinger 2015; Johnson et al. 2018). Behavioral traits that mediate interactions among conspecifics, like sexual displays, are also sex steroid dependent (Bass 2008; Bass and Remage-Healey 2008; Zornik and Kelley 2011) and can arise convergently (Trillmich and Trillmich 1984; Ord et al. 2013). Thus, sex steroid system evolution may also play a role in this process. One possibility, for instance, is that the convergent evolution of certain behavioral traits is marked by similar modifications to the underlying mechanisms of sex steroid action. However, an alternative scenario is that the same behavioral trait in two unrelated species is mediated by entirely different steroid system adaptations. Rarely (if ever) have studies explored these possibilities within a strong evolutionary framework, leaving a major gap in our knowledge of how hormone systems support adaptation of the vertebrate reproductive phenotype.

We address these ideas by describing hormonal signatures that mark the convergent evolution of frog "dance" displays. A hallmark of these displays is an elaborate gestural signal called the "foot-flag," which males produce by extending a hind limb above their head while rotating it backward in an arc. Foot-flagging is critical to mediating male-male competition for access to mates and/or breeding areas (Preininger et al. 2013), as studies suggest that it has arisen to augment sociosexual communication when acoustic signals are masked by environmental noise (Preininger et al. 2009; Grafe et al. 2012). Indeed, all foot-flagging species live and reproduce in extremely noisy habitats (e.g., fast-flowing streams, waterfalls; Hödl and Amézquita 2001;
Biju et al. 2014; Grafe and Tony 2017). We see foot-flagging behavior in at least eight genera, many of which are separated by millions of years of evolution (fig. 1). In this way, the foot-flagging display is an excellent example of convergent evolution, in which the same elaborate gestural display has repeatedly evolved in distinct anuran lineages to help solve the same social and ecological problems. Still, footflagging routines can vary slightly among species, particularly with respect to their overall complexity. Some taxa incorporate forms of toe tapping into their displays, whereas other taxa have evolved the ability to perform two simultaneous foot-flags with both hind limbs (Hödl and Amézquita 2001). Thus, studying foot-flagging also provides an opportunity to investigate behavioral diversity within a lineage and to link it to underlying physiological changes.

Research on the hormonal basis of foot-flagging has focused on Bornean rock frogs, or Staurois parvus. This work shows that the androgenic steroid testosterone (T) stimulates foot-flagging (Mangiamele et al. 2016). Moreover, the ability to produce this display appears to have evolved alongside a 10-fold increase in AR expression in the thigh musculature, which actuates the elaborate hind limb movements of the foot-flag (Prikryl et al. 2009), compared with species that do not foot-flag (Mangiamele et al. 2016). Thus, this work supports the hypothesis that selection drives the emergence of foot-flagging in part by enhancing the effects of androgenic steroids on certain muscle groups. Similar work in birds and lizards reveals that complex gestural displays (i.e., increased modifications to a species' display routine) appear to coevolve with dramatic increases in AR expression within select parts of the muscular system (Fuxjager et al. 2015; Johnson et al. 2018; Schuppe and Fuxjager 2019). Functionally, these populations of AR are thought to help reshape parameters of performance, which endow individuals with novel behavioral abilities necessary for display. Such effects can occur via androgen-dependent changes to muscle growth, fiber type composition, and calcium handling (Michel and Baulieu 1980; Sassoon et al. 1987; Brantley et al. 1993; Holmes et al. 2007; Fuxjager et al. 2012). Similarly, AR action within the muscle can feedback to the nervous system (Rand and Breedlove 1995), potentially regulating how cells in the spinal cord control motor output (Schlinger et al. 2018). With this work in mind, we investigate whether convergence in foot-flagging behavior is associated with similar increases in AR transcript abundance within the thigh muscles and/or central nervous system (CNS).

We approach this idea by performing several analyses that together paint a broad picture of the evolutionary relationship between foot-flagging behavior and AR expression. First, we test whether the presence or absence of footflagging in unrelated frog species predicts levels of AR transcription in the thigh muscles. If convergent evolution of this behavior occurs through similar modifications to 


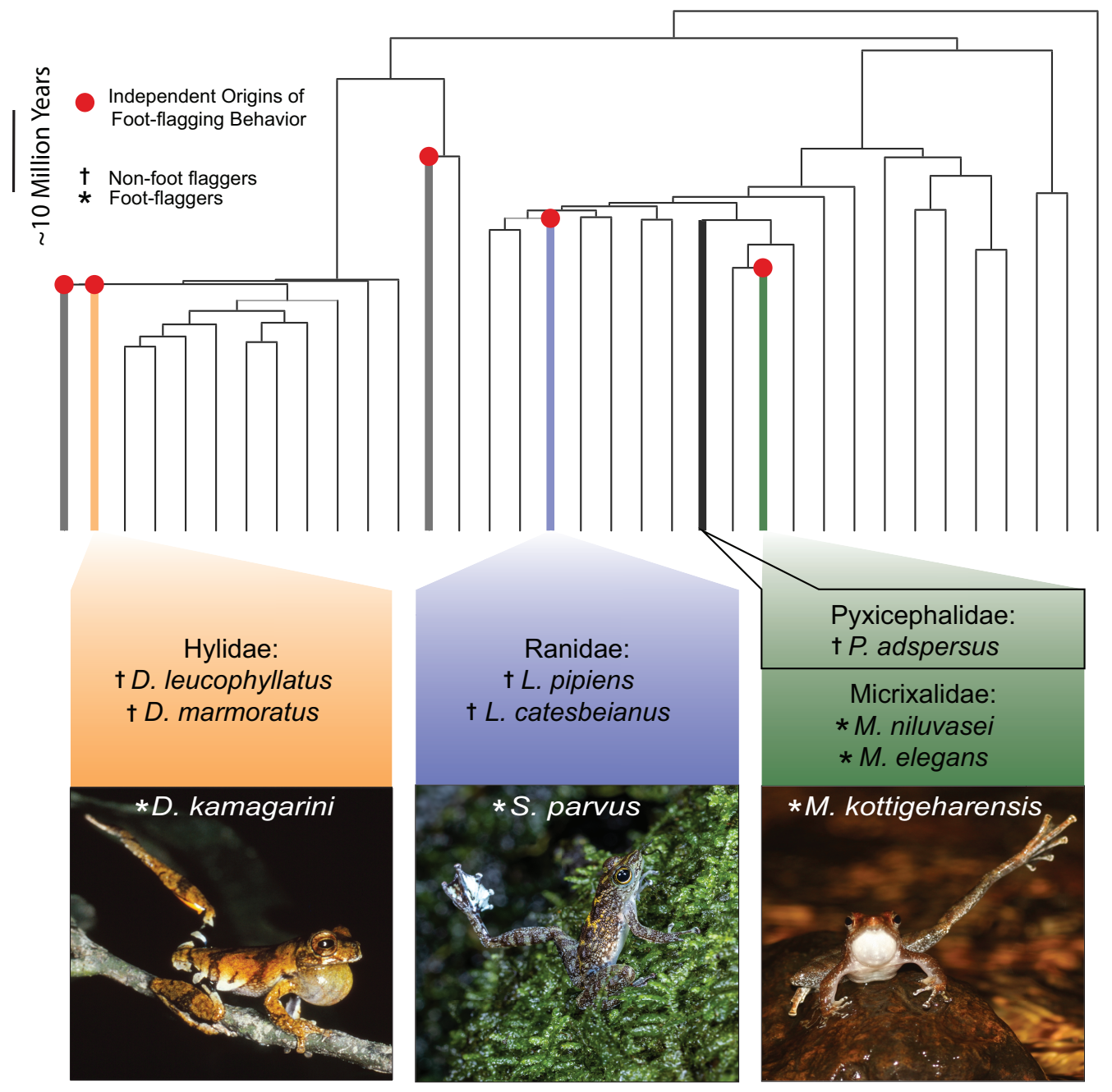

Figure 1: Family-level anuran phylogeny showing the distantly related clades from which we study foot-flagging behavior. Colored branches and corresponding colored boxes represent families from which we sampled foot-flagging and non-foot-flagging species, with green indicating Micrixalidae, blue indicating Ranidae, and orange indicating Hylidae. We compared the foot-flagging species in Micrixalidae with the nonfoot-flagging species Pyxicephalus adspersus in Pyxicephalidae; thus, it is included in the green box and denoted by a black outline. Note that the estimated evolutionary distance between Micrixalidae to $P$. adspersus is similar to the evolutionary distance between Staurois parvus and its non-foot-flagging relatives (see "Methods"). Gray branches highlight families that contain foot-flagging species that are not sampled in this study. Asterisks denote the foot-flagging taxa, whereas crosses denote the non-foot-flagging taxa. The phylogeny was pruned from Moen (2016), a family-wide phylogeny generated from the well-resolved phylogeny by Pyron and Weins (2011). Photographs by W. Hödl ( $D$. kamagarini) and D. Preininger (S. parvus and M. kottigeharensis) and used with permission.

the androgenic system, then we expect to see a positive relationship between these two variables after accounting for shared evolutionary history. In this analysis, we also look for a correlation between foot-flagging and AR expression in the CNS. Work in birds shows that species with high levels of AR in their muscles to support gestural display may also maintain elevated AR expression in other tissues, including much of the brain and spinal cord (Feng et al. 2010; Fuxjager et al. 2012). We therefore tested whether this pattern also occurs in foot-flagging frogs or whether we see evidence of tissue-specific increases in AR expression alongside innovations in foot-flagging. Next, we probe whether correlated evolution between foot-flagging and AR expression varies across the anuran phylogeny in a mosaic fashion, which refers to differences in coevolutionary linkage between variables among taxa (Thompson 2005; Swanson et al. 2006; Felice and Goswami 2018). This seems possible, considering that steroid systems evolve in response to various environmental and/or neutral factors (Adkins-Regan 2008; Fuxjager and Schuppe 2018; Schuppe 
et al. 2020). We therefore test this idea by conducting phylogenetic independent contrast comparisons (Garland 1992; Garland et al. 1999). Third, we examine whether standing variation in thigh muscle AR levels differs between foot-flagging species and their non-foot-flagging relatives. Sexually selected traits are often more variable than other traits at both phenotypic and genotypic levels (Ryan and Keddy-Hector 1992; Pomiankowski and Moller 1995; Rodríguez and Greenfield 2003; Hosken and Stockley 2004; Johnston et al. 2013), and thus we expect that levels of AR transcription are more variable in foot-flagging species, assuming that this trait is sexually selected. Fourth, we test whether differences in the overall complexity of footflagging routines among a small group of closely related frogs predict differences in AR levels within the muscular system and CNS. Past work finds that taxa with more complex gestural display routines express higher levels of AR in their muscles but not in certain parts of their CNS (but see statement above; Fuxjager et al. 2015). Collectively, these analyses address several different patterns of AR expression that might emerge in the motor system to support convergent innovations in sexual behavior.

\section{Methods \\ Animals}

All appropriate governmental and university authorities approved the methods described below. We used muscle and CNS tissue from 11 different frog species - five of which are known to foot-flag and six of which do not (fig. 1; ta- ble 1). All non-foot-flagging species were selected because they were the closest relatives to the foot-flagging taxa that we could reasonably obtain, with the exception of Xenopus laevis, which was used as an out-group. Accordingly, the foot-flagging Staurois parvus was paired with non-footflagging relatives within the same family, whereas the footflagging Dendropsophus kamagarini was paired with nonfoot-flagging relatives in the same genus. The three species of Indian dancing frogs from the genus Micrixalus were paired with a non-foot-flagging relative from a different family, Pyxicephalidae. Despite these taxonomic designations, groups of foot-flagging and non-foot-flagging species within our study (including the Pyxicephalid and the Micrixalids) are separated by similar spans of evolutionary time. We estimated evolutionary time by taking the known divergence of Micrixalidae from Ranidae 90 million years ago (Roelants et al. 2004) and comparing this value with the branch length proportions of our phylogeny. For example, S. parvus shared a common ancestor with the two non-foot-flagging Ranids in our study $\sim 60$ million years ago, while the recently diverged foot-flagging Micrixalus spp. all shared a common ancestor with the non-foot-flagging Pyxicephalid $~ 70$ million years ago. By contrast, the foot-flagging and non-footflagging Dendropsophus in our study were separated from each other by roughly half this time ( $\sim 30$ million years) compared with our Ranidae and Micrixalus species. Finally, as an additional comparison, we included the non-footflagging X. laevis in our study. Xenopus laevis diverged from the other taxa (Micrixiladae, Ranidae, Hylidae, etc.) $\sim 150$ million years ago.

Table 1: Foot-flagging species and their close non-foot-flagging relatives used in our study

\begin{tabular}{|c|c|c|c|c|c|}
\hline \multirow[b]{2}{*}{ Species } & \multirow[b]{2}{*}{ Family } & \multirow[b]{2}{*}{$\begin{array}{c}\text { Foot-flagging } \\
\text { behavior }\end{array}$} & \multirow[b]{2}{*}{$\begin{array}{l}\text { Population } \\
\text { source }\end{array}$} & \multicolumn{2}{|c|}{ Sample size $(n)$} \\
\hline & & & & $\begin{array}{l}\text { Thigh } \\
\text { muscles }\end{array}$ & $\begin{array}{c}\text { Neural } \\
\text { (brain and } \\
\text { spinal cord) }\end{array}$ \\
\hline Lithobates pipiens & Ranidae & Absent & CS & 5 & 3 \\
\hline Lithobates catesbeianus & Ranidae & Absent & CS & 5 & 6 \\
\hline Staurois parvus & Ranidae & Present $^{\mathrm{a}}$ & $\mathrm{ZC}$ & 7 & 4 \\
\hline Pyxicephalus adspersus & Pyxicephalidae & Absent & CS & 8 & 10 \\
\hline Micrixalus kottigeharensis & Micrixalidae & Present $^{\mathrm{b}}$ & WC & 8 & 6 \\
\hline Micrixalus niluvasei & Micrixalidae & Present ${ }^{\mathrm{b}}$ & WC & 8 & 8 \\
\hline Micrixalus elegans & Micrixalidae & Present $^{\mathrm{b}}$ & WC & 9 & 9 \\
\hline Dendropsophus leucophyllatus & Hylidae & Absent & $\mathrm{CS}$ & 9 & 10 \\
\hline Dendropsophus marmoratus & Hylidae & Absent & CS & 6 & 7 \\
\hline Dendropsophus kamagarini & Hylidae & Present $^{c}$ & WC & 6 & 6 \\
\hline Xenopus laevis & Pipidae & Absent & CS & 5 & 4 \\
\hline
\end{tabular}

Note: $\mathrm{ZC}=$ individuals from zoo collection; $\mathrm{WC}=$ individuals collected from wild population; CS = individuals obtained from commercial supplier but bred and reared in seminatural conditions (see "Methods").

${ }^{a}$ Grafe et al. (2012)

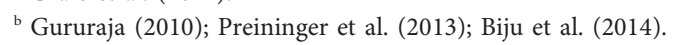

c Amézquita and Hödl (2004).

d Included as an out-group in the omnibus analysis. 
We used only reproductively active adult males of each species. This was verified by (i) conducting detailed behavioral observations of active courtship (displaying) and/ or sexual behavior (mate clasping) or (ii) documenting the presence of nuptial toe pads and/or enlarged testes discovered during dissection (see below). We obtained species by collecting them from the field or by acquiring them from private suppliers (including the Vienna Zoo) who rear and breed frogs in conditions that closely mimic the species' natural environment (e.g., outdoor breeding ponds, large indoor breeding enclosures with appropriate vegetation, temperature, humidity). Studies show that captive frogs housed in this manner maintain steroid hormone profiles that are similar to wild-caught individuals (Coddington and Cree 1995; Germano et al. 2009; Narayan et al. 2010), helping ensure that species differences in androgenic systems are not attributed to housing conditions. For fieldcollected specimens, we captured Micrixalus species during the breeding season in India, with $M$. niluvasei and $M$. kottigeharensis coming from Agumbe Hobli (Karnataka state) and M. elegans coming from Honey Valley Estate (Karnataka state). We captured D. kamagarini during the breeding season at Los Amigos Biological Station in Peru.

We euthanized individuals via rapid decapitation and immediately dissected the thigh muscular system and CNS (whole brain and spinal cord). As described elsewhere (Mangiamele et al. 2016), we focused on thigh muscles because they actuate the major movements that underlie the foot-flag, including femoral extension, rotation, and retraction (Přikryl et al. 2009). We also focused on the whole CNS, as past work shows that AR expression can be higher in these tissues (even when measured at similar gross levels) in species that perform complex gestural displays (Feng et al. 2010; Fuxjager et al. 2012). Note that we combined brain and spinal cord samples, creating a single sample of neural tissue for each species. For all dissections, we first preserved tissues with RNAlater at $4^{\circ} \mathrm{C}$ overnight to allow infiltration into the tissue and then transferred them to a $-80^{\circ} \mathrm{C}$ freezer according to the manufacturer instructions. The one exception was Lithobates catesbeianus thigh muscle; these tissues were too large to immerse in RNAlater in a manner that was consistent with the other samples, so we quickly froze them on dry ice. Past work suggests that flash freezing does not appreciably influence measures of gene expression (including AR messenger RNA [mRNA]) in muscle and neural tissue (Fuxjager et al. 2015). All samples were stored continuously at $-80^{\circ} \mathrm{C}$ until further processing (see below).

\section{RNA Isolation and Reverse Transcription}

Before extracting RNA from each sample, we carefully removed any trace of tissue that was not muscle or CNS (e.g., bone fragments, skin). We then homogenized each sample in TRIzol reagent at medium speed for $30 \mathrm{~s}$ using a rotor/stator homogenizer. We then used Zymo Directzol RNA miniprep kits (Zymo Research, Irvine, CA) to extract RNA, adding a phenol-chloroform separation step to the procedure before proceeding to manufacturer's instructions. After this procedure, we ran samples on a $1 \%$ agarose gel to verify RNA integrity and to confirm the absence of genomic DNA. We ended this workflow by measuring RNA concentrations with a NanoDrop (ThermoFisher, model 1000) and storing the samples at $-80^{\circ} \mathrm{C}$ until further processing. All sample concentrations were greater than $300 \mathrm{ng} / \mu \mathrm{L}$.

We reverse transcribed RNA samples into complementary DNA (cDNA). To begin the process, we treated samples with RNase-free DNase I (New England Bioscience) at $37^{\circ} \mathrm{C}$ for $20 \mathrm{~min}$ to ensure that traces of genomic DNA were digested. We then subjected samples to a heatdeactivated step at $75^{\circ} \mathrm{C}$ for $10 \mathrm{~min}$ to inactivate DNase enzyme and thus prevent interference with cDNA synthesis. Next, we added oligo $(\mathrm{dT})_{20}$ and dNTPs to $1 \mu \mathrm{g}$ of total RNA for each sample, incubating the mixture at $65^{\circ} \mathrm{C}$ for $5 \mathrm{~min}$ and then on ice for $1 \mathrm{~min}$. We followed this step by adding additional ingredients to mediate the reverse transcriptase reaction, including SuperScript IV reverse transcriptase, SuperScript IV buffer, dithiothreitol, and RNaseOUT. We incubated samples at $55^{\circ} \mathrm{C}$ for $10 \mathrm{~min}$, followed by $80^{\circ} \mathrm{C}$ for $10 \mathrm{~min}$, following the manufacturer's instructions. When finished, we ran samples on a $1 \%$ agarose gel and NanoDrop to confirm that cDNA was synthesized.

\section{Identification of $A R$ mRNA Sequence}

We amplified segments of AR and glyceraldehyde-3phosphate dehydrogenase (GAPDH) genes in each species included in our study. We accomplished this using degenerate AR primers and GAPDH primers, which were developed in túngara frogs (Chakraborty and Burmeister 2010; Mangiamele et al. 2016). We performed polymerase chain reactions (PCRs) using $40 \mathrm{ng}$ from the CNS and thigh muscle tissue of each species, mixing this with $0.5 \mu \mathrm{M}$ of forward primer, $0.5 \mu \mathrm{M}$ of reverse primer, and OneTaq $2 \mathrm{X}$ master mix (New England Biolabs). We first ran reactions at $96^{\circ} \mathrm{C}$ for $5 \mathrm{~min}$ and then subjected each sample to 35 cycles of $96^{\circ} \mathrm{C}$ for $30 \mathrm{~s}, 55^{\circ} \mathrm{C}(\mathrm{AR})$ or $57^{\circ} \mathrm{C}(\mathrm{GAPDH})$ for $30 \mathrm{~s}$, and $68^{\circ} \mathrm{C}$ for $30 \mathrm{~s}$. We completed these reactions with a final extension step at $68^{\circ} \mathrm{C}$ for $5 \mathrm{~min}$. PCR products were then run on a $1 \%$ agarose gel and imaged to confirm that amplified fragments equaled their expected size. Finally, we excised PCR products from the gel and purified them using a GeneJET PCR purification kit (ThermoFisher). We then sent these samples to Eton Bioscience for Sanger sequencing. Transcripts among the species were highly homologous, with AR (between 81\% and 95\%) and GAPDH 
(between $82 \%$ and $98 \%$ ) exhibiting strong sequence identity among anuran taxa.

\section{Relative Quantitative PCR}

We used quantitative PCR (qPCR) to measure levels of AR transcript (mRNA) expression in thigh muscle and CNS tissue of all 11 species. When using this technique, accurate quantification of any gene of interest requires that transcript abundance be standardized to an internal control gene (i.e., housekeeping gene), which is expressed equally across all tissues/samples subject to experimental comparison. The use of one housekeeping gene is a common practice, assuming that it is constitutively expressed for the tissues under investigation (Bauer et al. 2018; Nowicki et al. 2020; Sikkink et al. 2020). Here, we use the housekeeping gene GAPDH, which is a stable reference gene in frogs (Park et al. 2006; Nogawa-Kosaka et al. 2010; Trujillo et al. 2015) and is suitable for both skeletal muscle (Jemiolo and Trappe 2004; Mahoney et al. 2004; Touchberry et al. 2006) and neural tissues (Gebhardt et al. 2010; Stassen et al. 2015). Moreover, we confirmed that amplification levels of GAPDH were similar among species for both thigh muscles and neural tissue (two-way ANOVA; species effect: $F_{10,213}=1.22, P=.28$; tissue effect: $F_{1,213}=2.93, P=.09$; species $\times$ tissue: $F_{10,213}=1.54$, $P=.13$ ). Only one species in our study $-S$. parvusshowed signs of higher GAPDH specifically in the CNS compared with the other taxa (albeit not enough to drive a statistically significant effect in our analysis above). To verify that this particular species did not influence any of our findings regarding differences in AR in the CNS, we reran analyses that incorporated these variables without $S$. parvus and found no difference in any statistical outcome $(t=1.015, \lambda<0.01, P=.340)$. Thus, any perceived anomaly in GAPDH expression in the CNS of $S$. parvus had little effect on our results.

Detailed descriptions of qPCR workflow, optimized to study gene expression in nonmodel frog species, are outlined elsewhere (Mangiamele et al. 2016). Briefly, we performed reactions using an Applied Biosystems QuantStudio 3 machine with species-specific primers (table 2) designed from the amplified segments of the AR and GAPDH genes described above. We followed best practice

Table 2: Forward and reverse primers for each species used in quantitative polymerase chain reaction (qPCR) to measure androgen receptor $(A R)$ expression and gylceraldehyde-3-phosphate dehydrogenase (GAPDH) expression in the thigh musculature and neural tissue

\begin{tabular}{|c|c|c|}
\hline Species, gene & Forward primer & Reverse primer \\
\hline \multicolumn{3}{|c|}{ Staurois parvus: } \\
\hline$A R$ & AATGCCTTTGCCCACTTCAC & AACCAGCCTGACAGTTTTGC \\
\hline GAPDH & CAACAACATACATGGGGGCATC & ACCATGAAAAGGCTTCTGC \\
\hline \multicolumn{3}{|c|}{ Xenopus laevis: } \\
\hline$A R$ & TGCCAGCCTATCTTCCTGAATG & AGCAAAGCAAAGCTGTGCTGG \\
\hline GAPDH & ACAGTCCATGCTTTCACTGC & ACTTTTCCGACAGCCTTTGC \\
\hline \multicolumn{3}{|c|}{ Lithobates pipiens: } \\
\hline$A R$ & AATGCCTTTGCCCACTTCAC & AACCAGCCTGACAGTTTTGC \\
\hline GAPDH & CAACAACATACATGGGGGCATC & ACCATGAAAAGGCTTCTGC \\
\hline \multicolumn{3}{|c|}{ Lithobates catesbeianus: } \\
\hline$A R$ & AATGCCTTTGCCCACTTCAC & AACCAGCCTGACAGTTTTGC \\
\hline GAPDH & CAACAACATACATGGGGGCATC & ACCATGAAAAGGCTTCTGC \\
\hline \multicolumn{3}{|c|}{ Micrixalus kottigeharensis: } \\
\hline$A R$ & TGACAACAACCAGCCTGACA & TGGTAATGCCTTTGCCCACT \\
\hline GAPDH & CTGGCTCCTCTTGCAAAGGT & AGCATGGACAGTGGTCATCA \\
\hline \multicolumn{3}{|c|}{ Micrixalus niluvasei: } \\
\hline$A R$ & TGACAACAACCAGCCTGACA & TGGTAATGCCTTTGCCCACT \\
\hline$G A P D H$ & CTGGCTCCTCTTGCAAAGGT & AGCATGGACAGTGGTCATCA \\
\hline \multicolumn{3}{|c|}{ Micrixalus elegans: } \\
\hline$A R$ & TGACAACAACCAGCCTGACA & TGGTAATGCCTTTGCCCACT \\
\hline GAPDH & ACTGTCCATGCTTACACTGC & ATGTTCTGTCCAGCACCTCT \\
\hline \multicolumn{3}{|c|}{ Pyxicephalus adspersus: } \\
\hline$A R$ & GGACATGTTTGGTGTCATCTCTC & AGAAGTTGGGTAATCTGAAGGC \\
\hline GAPDH & GTCCATGCTTACACTGCTACAC & ATGTTCTGTCCAGCACCTCTG \\
\hline \multicolumn{3}{|c|}{ Dendropsophus leucophyllatus: } \\
\hline$A R$ & AGTGGGCAAAGGCATTACCA & ATAAGGCCCATCCAGGAGTACT \\
\hline GAPDH & GTCCATGCTTACACTGCTACAC & ATGTTCTGTCCAGCACCTCTG \\
\hline
\end{tabular}


Table 2 (Continued)

\begin{tabular}{lll}
\hline Species, gene & \multicolumn{1}{c}{ Forward primer } & \multicolumn{1}{c}{ Reverse primer } \\
\hline $\begin{array}{l}\text { Dendropsophus marmoratus: } \\
\text { AR }\end{array}$ & AGTGGGCAAAGGCATTACCA & ATAAGGCCCATCCAGGAGTACT \\
GAPDH & GTCCATGCTTACACTGCTACAC & ATGTTCTGTCCAGCACCTCTG \\
Dendropsophus kamagarini: & & \\
AR & AGTGGGCAAAGGCATTACCA & ATAAGGCCCATCCAGGAGTACT \\
GAPDH & GTCCATGCTTACACTGCTACAC & ATGTTCTGTCCAGCACCTCTG \\
\hline
\end{tabular}

guidelines for designing robust and effective qPCR primers, which are outlined elsewhere (Nolan et al. 2006; Bustin et al. 2009; Johnson et al. 2014). Each qPCR reaction contained $100 \mathrm{ng}$ of cDNA, $0.9 \mathrm{mM}$ of forward primer, $0.9 \mathrm{mM}$ of reverse primer, and SYBR green master mix (Applied Biosystems). We ran reactions with the following parameters: $50^{\circ} \mathrm{C}$ for $2 \mathrm{~min}, 95^{\circ} \mathrm{C}$ for $10 \mathrm{~min}$, and 40 cycles of $95^{\circ} \mathrm{C}$ for $15 \mathrm{~s}$ and $60^{\circ} \mathrm{C}$ for $1 \mathrm{~min}$. We then ran a final dissociation stage that consisted of $95^{\circ} \mathrm{C}$ for $15 \mathrm{~s}, 60^{\circ} \mathrm{C}$ for $30 \mathrm{~s}$, and $95^{\circ} \mathrm{C}$ for $15 \mathrm{~s}$. We always included no-template controls in our runs, none of which showed evidence of amplification. We ran all samples in duplicate, using the standard curve method to quantify relative expression of AR based on pooled cDNA samples from muscle and CNS tissue of multiple individuals (Pfaffl 2001). Reaction efficiencies for all qPCR runs used in our data set were between $90 \%$ and $110 \%$, reflecting best practice in the field.

We also implemented two main standard quality controls for our data. First, we checked that dissociation curves of both genes in all species produced a single sharp peak. This indicates that our reactions reliably amplified a single amplicon across taxa. Second, we used mRNA values associated with cycle threshold levels that did not exceed 35, which is considered the threshold above which contamination can influence the results (Nolan et al. 2006). The raw data have been deposited in the Dryad Digital Repository (https://doi.org/10.5061/dryad.3n5tb2rhh; Anderson 2021).

\section{Statistical Analyses}

We used a pruned ultrametric phylogenetic tree of anurans from Pyron and Wiens (2011) for all of our analyses. This tree includes all of the species used in our current study; however, two species in the tree-M. niluvasei and Dendropsophus parviceps - were recently split into additional taxa. In both cases, we collected individuals at or near populations whose sequences are included in the original Pyron and Wiens (2011) phylogeny, and thus our (i) Mi- crixalus fuscus is similar to M. niluvasei and (ii) D. kamagarini is similar to $D$. parviceps.

We first tested whether there is correlated evolution between foot-flagging behavior and levels of AR mRNA expression in thigh muscle and CNS tissues (see above). We conducted this analysis using the phylolm package (Ho et al. 2018) and thus ran a phylogenetic linear regression model with the presence or absence of foot-flagging assigned as a categorical independent variable and species' average AR mRNA level assigned as a continuous dependent variable. We simultaneously fitted the two models with maximum likelihood estimates of Pagel's coefficient of relatedness $\lambda$ to estimate phylogenetic signal and account for relatedness between species (Pagel 1999; Revell 2010). This approach allows traits to evolve under modified Brownian motion (BM) in which $0 \leq \lambda \leq 1$. Estimates of $\lambda$ that are closer to 0 indicate that traits are evolving in a way that is more independent of the phylogenetic relatedness across taxa, whereas estimates of $\lambda$ that are near (or at) 1 indicate that traits are evolving under complete BM.

We next wanted to examine whether patterns of the correlated evolution between foot-flagging and AR expression in thigh muscle showed signs of differing across three major anuran clades. We conducted this analysis using a phylogenetic independent contrast (PIC) comparative approach, in which the interclade relationship of correlated evolution is assessed through the magnitude of single PIC values for each clade (Felsenstein 1985; Garland 1992). This method allowed us to qualitatively compare the contrast in AR transcript levels in thigh muscle between foot-flagging species and non-foot-flagging relatives between anuran clades while simultaneously conserving phylogenetic relatedness. To do this, we used the PIC function from the package ape (Paradis et al. 2004) to first calculate standardized, single PIC values for each clade, contrasting the mean AR values of foot-flagging species to non-foot-flagging species. To ensure that each clade had only two nodes for the contrast, we took the PIC from the most recent nodes that connect our non-foot-flagging and foot-flagging species. We then 
compared the subsequent standardized PIC values for each clade, interpreting a higher PIC score as evidence that, within a given clade, the foot-flagging species evolved higher levels of AR mRNA in thigh muscle than non-foot-flagging relatives. Furthermore, to evaluate differences in the evolutionary response of thigh muscle AR among clades, we compared observed PIC values with simulated PIC values derived from a null distribution of thigh muscle AR values generated from non-foot-flagging species. To do this, we created a normal distribution of AR mRNA levels from the mean and standard deviations associated with each non-footflagging species. We then used values from this distribution to simulate AR values 100 times across our entire phylogeny (including the foot-flagging species) under a single-rate $\mathrm{BM}$ model using the fastBM function from the $\mathrm{R}$ package phytools (Revell 2012). We constrained our models to value ranges seen only in our non-foot-flagging species, and after each simulation, we calculated PIC values at the focal nodes for our three clades. We then compared these simulated PIC values from the null model with our actual observed PIC scores. In total, we repeated this procedure 100 times, using the proportion of times that simulated PIC values exceed the observed PIC values as a $P$ value that reflects a difference between the data (null vs. observed).

Because elements of sexually selected traits often show greater standing variation than non-sexually-selected traits (Ryan and Keddy-Hector 1992; Pomiankowski and Moller 1995; Rodríguez and Greenfield 2003; Hosken and Stockley 2004; Johnston et al. 2013), we assessed whether standing variation in AR levels of the thigh musculature differed between foot-flagging and non-foot-flagging taxa. We therefore calculated variance in AR abundance in thigh muscle for each species, then we ran $F$-tests to compare the variance of each foot-flagging species with that of its non-footflagging relatives. Higher standing variation in foot-flagging species may indicate that trait's potential susceptibility to evolution by sexual selection (David et al. 2000). We recognize that variation in $\mathrm{AR}$ expression may also come from qPCR measures, but such effects should be distributed equally among taxa in our analysis.

Last, we tested whether species variation in the complexity of foot-flagging routines was associated with species differences in $\mathrm{AR}$ of the thigh muscle and neural tissue. Often, foot-flagging is one component of a multimodal display in which frogs also vocalize and perform a series of other gestures (e.g., toe taps). Micrixalus species seem to each possess a similar number of these display components in their signaling routines, and thus we can focus on only the foot-flagging component to define differences in the complexity of their display repertoire. Thus, we define footflagging display complexity by the number of limbs simultaneously used in the display. We compared three Micrixalus species: M. niluvasei and M. kottigeharensis, which have simpler foot-flagging routines (single foot-flags), and $M$. elegans, which has more a complex routine (simultaneously foot-flags with both hind limbs). Using the package lme4 (Bates et al. 2014), we compared these species by running linear models in which species was the independent variable and AR mRNA abundance was the dependent variable. Significant effects were followed by a Tukey's honestly significant difference post hoc analysis.

All analyses were run in R Studio (https://www.rstudio .com), an integrated environment for R (https://www.r -project.org). We used the standard Tukey method to identify and remove extreme outliers from the data set (values that were three times greater or lower than the population interquartile range; Tukey 1977). Accordingly, this heuristic suggested removing one value each for S. parvus, L. catesbeianus, and Dendropsophus marmoratus. We then applied a log transformation to our raw data to ensure that they were normally distributed for subsequent parametric analyses.

\section{Results}

\section{Interspecific Variation across Anuran Phylogeny}

If similar modifications to the androgenic system underlie the convergent evolution of foot-flagging behavior, then distantly related taxa that produce this display should similarly express elevated AR in the thigh muscles compared with non-foot-flagging frogs. We tested this idea by quantifying AR transcript abundance in the thigh muscle and CNS of five unrelated foot-flagging taxa, as well as their non-foot-flagging relatives. Our phylogenetic linear regression model shows that the presence of foot-flagging positively predicts high levels of AR expression in the thigh musculature $(t=4.093, \lambda<0.01, P=.003$; fig. $2 a)$ but not in the CNS $(t=1.071, \lambda<0.01, P=.312$; fig. $2 b)$. Moreover, species differences in muscular AR abundance are not associated with AR abundance in the CNS $(t=$ 1.347, $\lambda<0.01, P=.211)$. These results therefore collectively point to correlated evolution between foot-flagging behavior and AR levels in the peripheral tissues that actuate this signal.

\section{Mosaic Correlated Evolution between Foot- Flagging and Muscular AR}

We next explored whether correlations between footflagging and muscular AR differed across the phylogeny by comparing PIC values among the clades (fig. 3). For Staurois parvus and the Micrixalus species, PIC values were high -0.0230 and 0.0312 , respectively — and both were statistically distinguishable from PIC values derived through a simulated null scenario (both species: $P<.01$ ). Meanwhile, the PIC value between Dendropsophus kamagarini 
a)

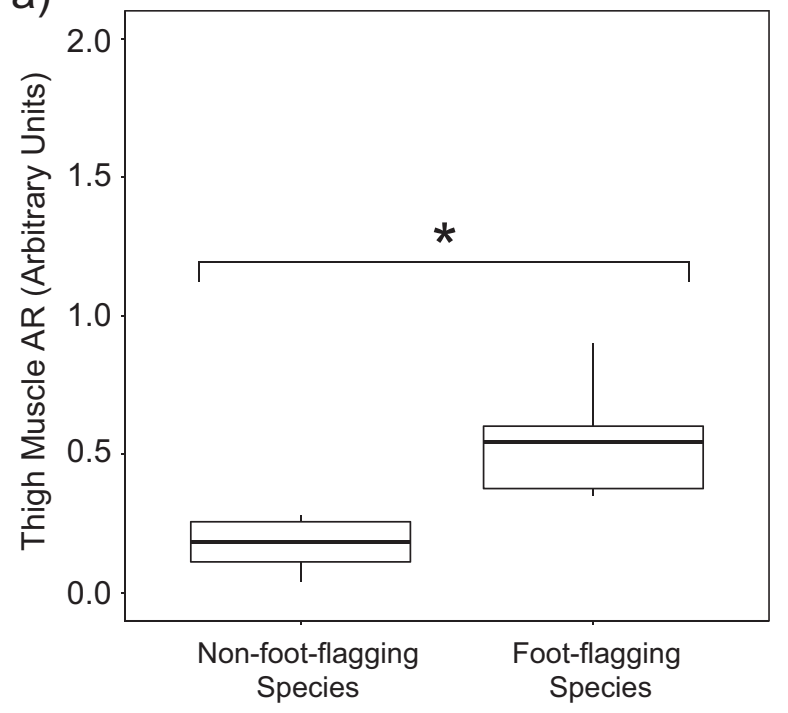

b)

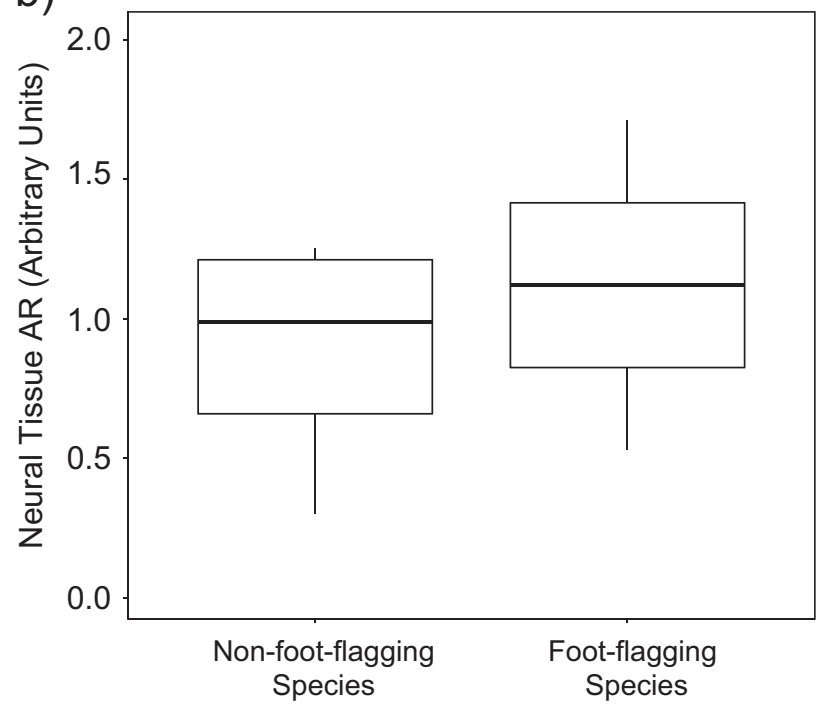

Figure 2: Boxplots of androgen receptor (AR) messenger RNA expression in the thigh musculature $(a)$ and neural (central nervous system; $b$ ) tissue between foot-flagging and non-foot-flagging species. For each boxplot, the central line represents the median of the data; the top and bottom of the box represent the first and third quartiles, respectively; and the whiskers represent 1.5 times the interquartile range. Significant differences between groups $(P<.05)$ are denoted with an asterisk.

and its non-foot-flagging relatives was much lower0.0117 - and it was statistically indistinguishable from the null model $(P=.320)$. These results indicate that differences in AR transcript abundance in hind limb muscles between foot-flagging taxa and their non-foot-flagging relatives were greatest for both the Micrixalus frogs and the Ranids.

\section{Intraspecific Variation between Foot-Flagging and Non-Foot-Flagging Species}

We compared levels of standing variation in muscular AR expression of the different species within each clade, expecting that foot-flagging species would show greater variation than their non-foot-flagging relatives. This prediction is based on the observation that components of sexual traits often show greater phenotypic variation than nonsexual ones. Indeed, our analyses show significant species differences in patterns of standing variation in AR transcript abundance of the thigh musculature (fig. 4). For Ranidae, $S$. parvus shows higher standing variation compared with its non-foot-flagging relatives (Lithobates pipiens: $F_{6,4}=$ 1,533.2, $P<.001$; Lithobates catesbeianus: $F_{6,4}=204.3$, $P<.001)$. For Micrixalidae, Micrixalus niluvasei $\left(F_{7,7}=\right.$ $11.78, P=.004)$ and Micrixalus elegans $\left(F_{8,7}=31.67\right.$, $P<.001)$ both show higher standing variation compared with the non-foot-flagging Pyxicephalus adspersus. However, we also find that standing variation is similar between some foot-flagging species and their non-foot-flagging rel- atives. Micrixalus kottigeharensis $\left(F_{7,7}=3.201, P=.148\right)$ shows levels of standing variation similar to $P$. adspersus, whereas $D$. kamagarini shows standing variation similar to both Dendropsophus leucophyllatus $\left(F_{8,5}=4.133, P=\right.$ $.135)$ and Dendropsophus marmoratus $\left(F_{5,5}=0.305, P=\right.$ .219). These findings partially conform to our expectations of variation in a sexually selected trait, if sexual selection in fact drives the evolution of foot-flagging.

\section{Interspecific Variation within the Family Micrixalidae}

In a final analysis, we examined whether species variation in the complexity of foot-flagging routines predicts relative levels of AR in thigh muscles and CNS in Micrixalus frogs. Past work shows that $M$. kottigeharensis foot-flags by extending and lifting one hind limb at a time, slowly arching it outward and then backward to display translucent gray foot webbing. Similarly, M. niluvasei extends, lifts, and arches one hind limb at a time to display dark reflective foot webbing. By contrast, $M$. elegans exhibits a more complex display routine, in that either it foot-flags one leg at a time like the other two taxa or it simultaneously extends both hind limbs backward while arching the appendages to display bright white foot webbing. In this sense, M. elegans maintains a more complex display repertoire than its congeners. Contrary to our initial predictions, we find no difference in AR mRNA levels among these three species with respect to the thigh muscles 


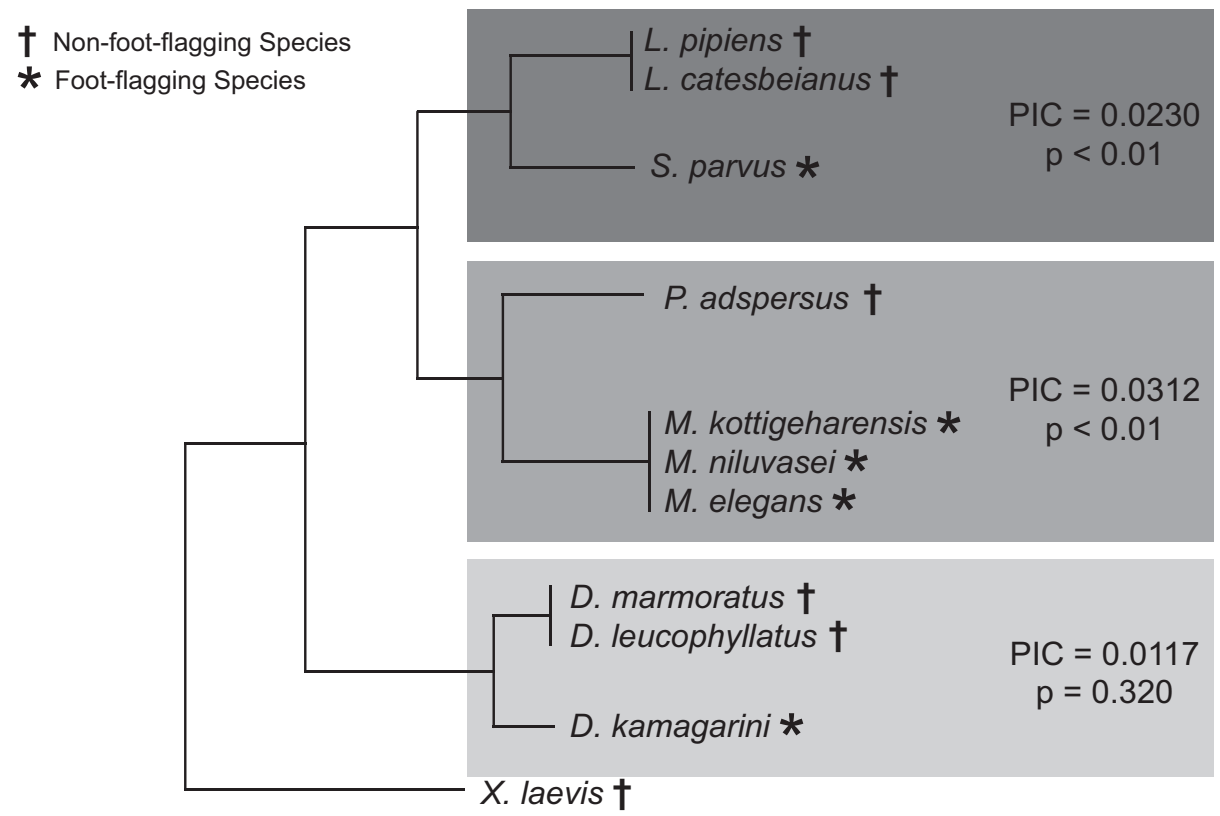

Figure 3: Plots showing cladal differences in correlated evolution between foot-flagging thigh muscle androgen receptor (AR) messenger RNA expression. The phylogeny on the left showcases the foot-flagging and non-foot-flagging species that are members of each clade (denoted by separate gray boxes; top to bottom: Ranidae, Micrixalus, and Hylidae). Asterisks denote foot-flagging species, whereas crosses denote non-foot-flagging species. Adjacent to the phylogeny are the single phylogenetic independent contrast (PIC) scores, with higher scores representing a higher contrast in thigh muscle AR transcript level between foot-flagging and non-foot-flagging species. Note the $P$ values, which indicate whether the observed PIC value was significantly different $(P<.05)$ than the PIC value derived from a simulated null distribution.

$\left(F_{2,22}=0.36, P=.70\right.$; fig. 5$)$. However, we do find a species difference in AR transcript abundance in the CNS $\left(F_{2,20}=59.1, P<.001\right.$; fig. 5$)$, with post hoc tests showing that $M$. elegans expresses less AR mRNA in neural tissue than either $M$. kottigeharensis $(P<.001)$ or $M$. niluvasei $(P<.001)$, although the latter two species were statistically indistinguishable from one another $(P=.310)$.

\section{Discussion}

Through a series of comparative analyses, our findings suggest that convergent evolution of a novel display in frogs arises through common adaptations to the androgenic hormone system. This conclusion is based on a positive correlated evolutionary relationship between an unusual dance display - the foot-flag - and significantly elevated levels of AR transcription in the musculature that actuates this behavior (Přikryl et al. 2009). Importantly, such a relationship is not evident in the nervous system, a finding that is contrary to past work that indicates that gross measures of $\mathrm{AR}$ in the CNS are similarly higher in taxa that produce highly elaborate gestural displays (Feng et al. 2010; Fuxjager et al. 2012). Accordingly, we hypothesize that elevated AR in the thigh muscles is an adaptive trait, given that androgenic activation of these receptor populations likely promotes foot- flagging behavior when males compete for access to female mates and resources (Mangiamele et al. 2016; Mangiamele and Fuxjager 2018). Selection for foot-flagging may therefore proceed in unrelated taxa by driving similar specializations to the endogenous androgenic system of specific tissues within the body.

We also report evidence that the magnitude of the evolutionary change in thigh muscle $\mathrm{AR}$ and its association with the origins of foot-flagging vary among species. For instance, we find striking phylogenetic differences in contrast values for thigh muscle AR between foot-flagging species and their non-foot-flagging relatives. For Staurois parvus and the Micrixalus species, levels of muscular AR result in a high PIC value compared with their non-foot-flagging relatives. However, for Dendropsophus kamagarini, AR levels appear to evolve only a slight increase alongside the emergence of foot-flagging. Explaining why these differences exist is challenging because the answer is likely linked to a host of factors related to each of the species' biogeography, ecology, physiology, and so on (see below for a discussion of physiological factors). Nonetheless, the results suggest that the robust correlated evolution between footflagging displays and components of the androgenic system evolves in a mosaic fashion, whereby the rate and magnitude of change in endocrine phenotype differs among taxa. 


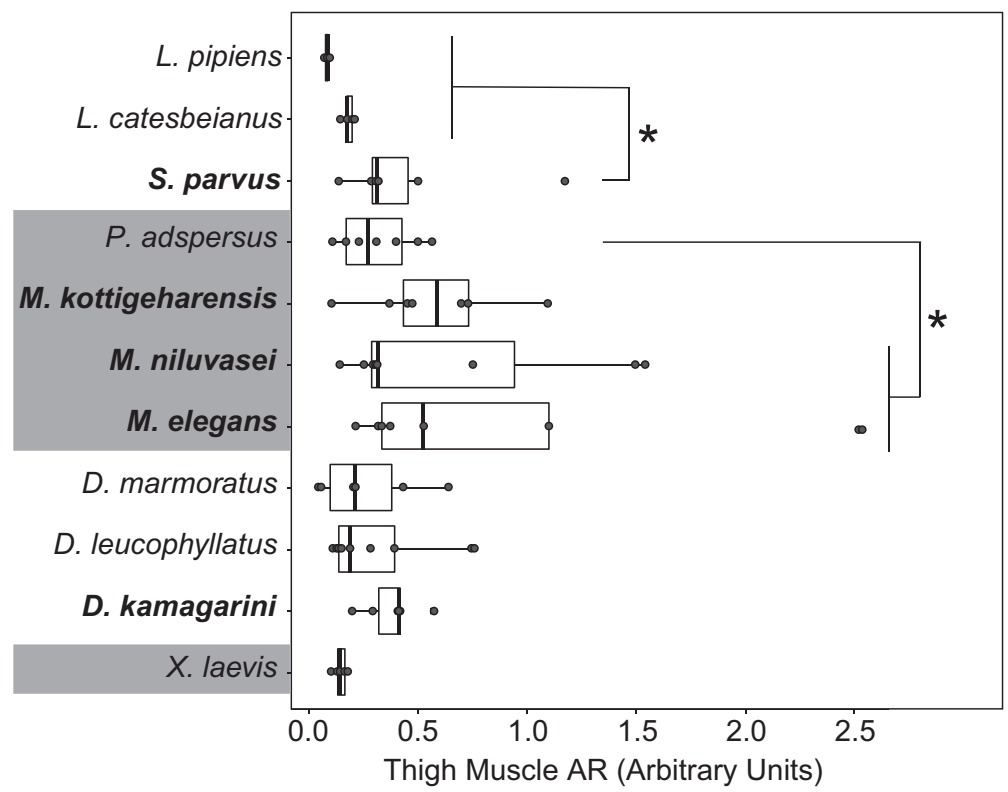

Figure 4: Boxplots of androgen receptor (AR) messenger RNA expression in thigh muscle for each foot-flagging and non-foot-flagging species used in our study. For each boxplot, the central line represents the median of the data; the top and bottom of the box represent the first and third quartiles, respectively; and the whiskers represent 1.5 times the interquartile range. Comparisons were made for the variance, or standing variation, between each foot-flagging species and its non-foot-flagging relatives. Gray coloring on the vertical axis denotes clades in which comparisons were made. Significant differences in these comparisons of standing variation between a single foot-flagging species and related non-foot-flagging species are denoted by asterisks.

Standing variation in muscular AR is generally greater in many foot-flagging frogs compared with their non-footflagging relatives. These effects are most pronounced in S. parvus and the Micrixalus frogs (except for M. kottigeharensis). Past work suggests that standing variation itself provides a route for selection to drive phenotypic adaptation (Prezeworski et al. 2005; Chenoweth and McGuigan 2010; Lai et al. 2019; Olofsson et al. 2019), with several studies pointing out that many sexually selected traits are far more variable than ones not under sexual selection (Ryan and Keddy-Hector 1992; Pomiankowski and Moller 1995; Rodríguez and Greenfield 2003; Hosken and Stockley 2004; Johnston et al. 2013). Thus, greater variation in muscular AR in foot-flagging frogs could provide a route for hormonemediated gestural displays to evolve and perhaps even serve as a signature of these effects over time. Discussion of how this variation is maintained while under intense selection is beyond the scope of this article (but see Tomkins et al. 2004; Bonilla et al. 2016), and questions remain about why other foot-flagging species like D. kamagarini do not show greater standing variation in AR. Nevertheless, these differences speak to the complex history of the coevolutionary ties between innovation in anuran display behavior and AR levels.

Finally, we find no evidence that levels of muscular AR transcription in the Micrixalus frogs vary with the overall complexity of their foot-flagging routines. Micrixalus elegans can produce foot-flags with either one hind limb or both hind limbs simultaneously, whereas the other two Micrixalus spp. foot-flag with only one leg at a time (Biju et al. 2014; M. J. Fuxjager, D. Preininger, and K. V. Gururaja, personal observations). Past work in other species indicates that muscular AR positively correlates with the overall complexity of species' display routines, particularly when complex displays are considered as those in which more discrete movement patterns are deployed in a signaling routine (sensu Fuxjager et al. 2015). Our findings in frogs do not support this idea, showing instead that a more complex foot-flagging routine does not necessarily occur in species that express more AR in their thigh. It is possible that the species differences in the complexity of footflagging routines are not great enough to observe a marked difference in muscular AR expression or that selection for foot-flagging in this family has driven the evolution of thigh vmuscle AR to a level that is functionally suitable to support the behavior and all of its variations. Alternatively, it is also possible that these particular differences in display complexity among Micrixalus are associated with differences in the androgenic regulation of the specific spinal cord motor circuits that control coordination of limb movements (Erulkar and Soller 1980). Testing this hypothesis would require measuring AR expression in lumbar spinal cord motoneurons via 
a)

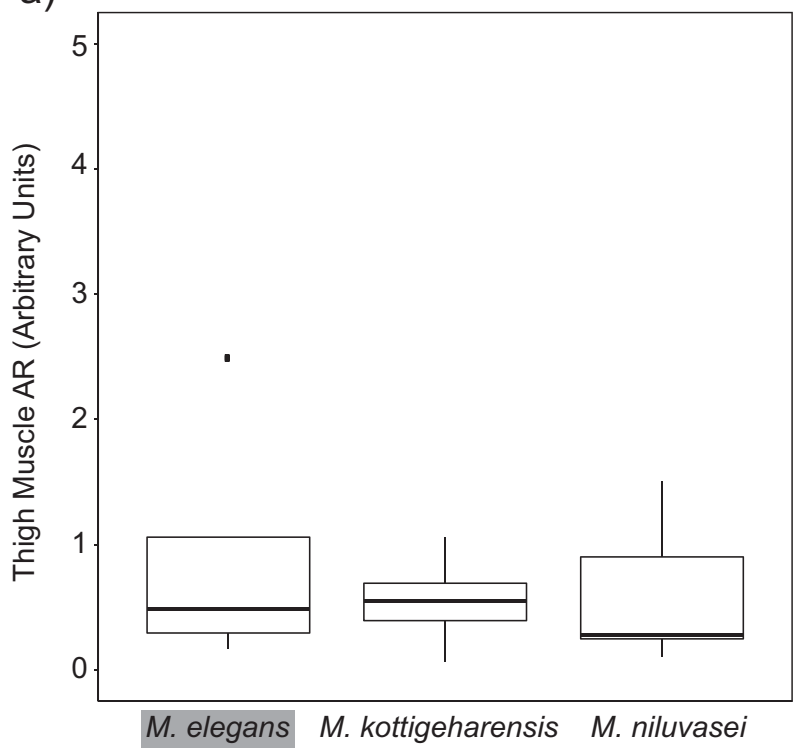

b)

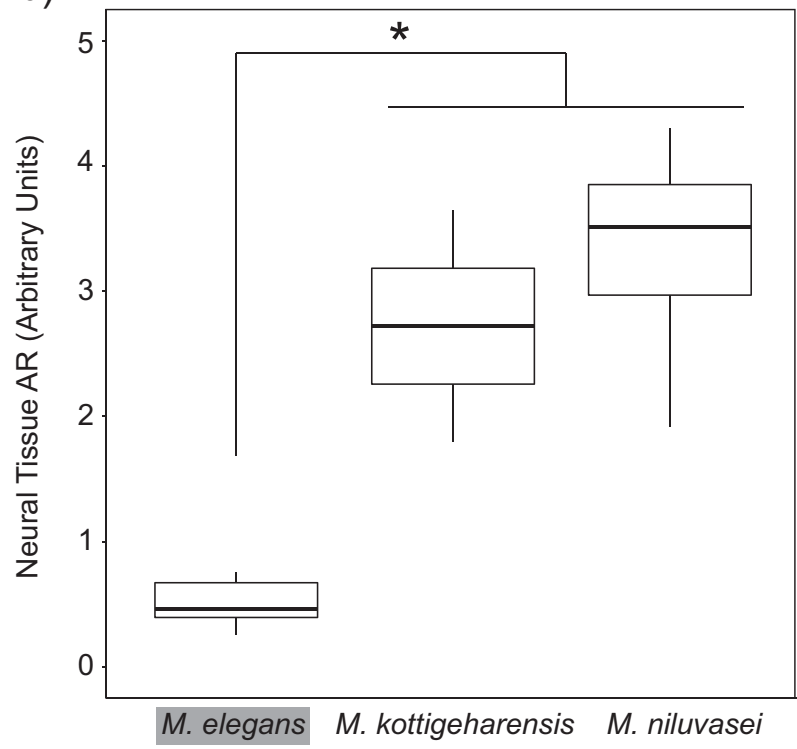

Figure 5: Boxplots showing the androgen receptor (AR) messenger RNA expression in the thigh musculature $(a)$ and neural (central nervous system; $b$ ) tissue of three Micrixalus species that vary in the complexity of their foot-flagging display. Micrixalus elegans has a more complex display routine, in which it either foot-flags with one leg or extends both legs simultaneously. Micrixalus kottigeharensis and M. niluvasei have less complex display routines, in which they extend only one leg at a time. Each species' boxplot denotes individual AR expression values, with the central line representing each species' median and the top and bottom lines representing the first and third quartiles, respectively. The whiskers show 1.5 times the interquartile range. Significant differences between groups $(P<.05)$ are denoted by an asterisk.

in situ hybridization, as qPCR can measure only overall tissue expression and not AR levels in specific cell populations.

Of course, we also find that M. elegans, the species with the more complex foot-flagging routine, shows significantly lower levels of AR transcripts in its neural tissue compared with the other Micrixalus taxa. On one hand, this result seems counterintuitive given that one might not expect a species with a more complex display routine to have less AR expression (see comments above). Yet these data are consistent with the idea that positive evolutionary relationships between elaborate gestural signaling and AR (or other mechanisms that enhance androgenic action such as through cofactors or local T synthesis) arise at the level of skeletal muscle and not the nervous system. This notion also lines up with our results showing no association between footflagging behavior and AR in the CNS more generally across all taxa in this study, as well as the broader idea that any number of ecological, physiological, and/or phylogenetic factors influence the evolution of the androgenic system in a mosaic fashion (at least through a macroevolutionary lens).

\section{Androgenic Hormone Systems as a Physiological Conduit for Behavioral Innovation}

Understanding the physiological basis of behavioral evolution is a major goal of organismal biology. Our data ad- dress this topic by pointing to androgenic hormone systems as a powerful conduit for the emergence of novel reproductive displays. In other words, when sexual selection favors the evolution of behavioral traits that demand specialized performance capability, it may proceed by simultaneously driving the evolution of AR systems in the associated skeletal muscles (Fusani et al. 2014a; Fuxjager and Schlinger 2015; Schuppe and Fuxjager 2019). Such effects can alter an organism's performance landscape, allowing individuals to produce novel motor patterns and altogether new types of behavior (Regnier and Herrera 1993a; Chambon et al. 2010; Wyce et al. 2010; Fuxjager et al.2017). This idea nicely dovetails with our current understanding of how androgens influence muscle-namely, they can regulate muscle cell growth (Michel and Baulieu 1980; Brantley et al. 1993), fiber type composition (Sassoon et al. 1987; Holmes et al. 2007), calcium handling (Fuxjager et al. 2012), and even morphological features of the tissue's innervating motor neurons (Rand and Breedlove 1995). Such effects occur in a wide range of species, suggesting that androgens' ability to influence muscle structure and function is a trait that arose deep within the vertebrate lineage. Bearing all of this in mind, we expect that AR-muscle interactions create an evolutionary path of least resistance in which selection can more easily refine the evolution of motor control (sensu Schluter 1996). 
From the perspective of evolutionary endocrinology, our data also support principles of the evolutionary potential hypothesis (EPH), which posits that components of sex steroid signaling systems can evolve independently of each other (Finch and Rose 1995; Hau 2007). Such effects may explain how changes in the reproductive phenotype arise during the course of evolution; for example, increasing receptor levels in one specific target tissue versus another may support the emergence of a particular trait. In our case, we see increases in AR expression in thigh muscles but not in the CNS of species that generate footflags, which (as we propose above) may represent a tissuespecific change to the androgenic systems that help mediate the display's performance. We also find that AR in the thigh muscle of foot-flagging frogs is not associated with AR expression in the CNS itself. This result also buoys the idea that changes in AR expression can occur independently across different target tissues (at least on a macroevolutionary scale), as elevated expression of AR appears to arise in muscle without a concomitant increase in AR expression elsewhere. Of course, our measures of AR expression in the CNS are quite gross - foot-flagging species may therefore show higher levels of AR in a few specific brain areas related to motor control, which in turn could be related to AR in the thigh. Such an effect would still support the EPH, as it would further reveal exquisite tissue- and/or nuclei-specific differences in AR expression linked to behavioral evolution. Future work will explore this issue by examining how neuroendocrine control changes to support the emergence of foot-flagging displays.

We should also note that EPH is fully consistent with our finding of mosaic correlated evolution between footflagging and AR abundance. In fact, bridging these two frameworks potentially provides insight into likely complexity of hormone systems diversification. We expect that species variation in the threshold at which androgen action regulates display output (Gupta et al. 1974) plays an important role in determining the extent to which AR levels evolve in a given frog. For instance, the Micrixalus species and $S$. parvus may transcribe higher levels of AR in the thigh muscle because they all require more robust androgenic stimulation of the musculature to generate a foot-flag compared with $D$. kamagarini. This pattern could be the result of species differences in circulating $\mathrm{T}$ levels among the taxa in our study; for example, Micrixalus spp. and S. parvus may have lower levels of circulating $\mathrm{T}$ relative to D. kamagarini and thus need higher levels of AR in their thigh to support the necessary androgenic regulation of these tissues. Another possibility is that higher or lower levels of AR evolve to balance species differences in the composition of intracellular machinery that transduces AR's effect. If, for instance, D. kamagarini expresses abundant coactivator in its thigh (which enhances andro- genic effects on the genome), then lower levels of AR expression may be sufficient to sustain foot-flagging. Certainly, species vary markedly in cofactor expression profiles, lending credence to this idea (Fuxjager and Schuppe 2018). A final explanation is that functional effects of AR differ across anurans because of variation in the genomic enrichment of androgen response elements (AREs), which is where ligand-bound AR interacts with the DNA to regulate gene expression (Fuxjager et al. 2016; Cox 2020). If taxa such as Micrixalus spp. and S. parvus have relatively lower genetic enrichment of AREs, then expressing more AR may be one way (among many) to overcome these effects.

\section{Endocrinology of Convergent Evolution}

More broadly, we hypothesize that endocrine systems play an important role in facilitating convergent evolution of several traits across the tree of life. This idea is based on two main lines of evidence. First, hormones often show functional biases toward the regulation of certain behaviors. Neuropeptides are prime examples - oxytocin and its homologues mediate pair bonding and social attachment in mammals, birds, and fish (Oldfield and Hofmann 2011; Pedersen and Tomaszycki 2012; Scheele et al. 2013; Numan and Young 2016), whereas arginine vasopressin and its homologues typically regulate facets of territoriality, aggression, and/or species recognition among mammals and fish (Insel et al. 1994; Young 1999; BesterMeredith and Marler 2001; Oldfield and Hofmann 2011). As discussed above, AR similarly shows functional biases, influencing sexual motor control in a wide range of species through actions at the level of the muscle (Sassoon et al. 1987; Brantley et al. 1993; Regnier and Herrera 1993b; Veney and Wade 2004; Holmes et al. 2007; Feng et al. 2010; Fuxjager et al. 2015; Mangiamele et al. 2016; Schuppe et al. 2017; Johnson et al. 2018; Schuppe and Fuxjager 2019). Taken together, these findings suggest that selection on specific suites of behavior may occur most efficiently through targeted effects on distinct arms of the endogenous endocrine system.

The second line of support for our hypothesis centers around the fact that endocrine systems are likely highly labile, easily responding to selection pressure. This is because even slight changes to the expression profile of hormone receptors and their underlying signaling machinery can confer major changes to the functional outcome of hormone action, particularly with respect to behavior. Indeed, changes to systems of gene regulation - such as receptor expression - can provide a powerful pathway for phenotypic adaptation (Abzhanov et al. 2006; Rebeiz et al. 2009; Manceau et al. 2011). Researchers even speculate that when gene regulation facilitates evolution, phenotypic 
change can occur more rapidly (Harrison et al. 2012). Future work will be needed to explore this idea further. Ideally, we can begin to produce large-scale comparative studies that chart how hormone receptor distributions change over time and potentially change alongside adaptive shifts in behavior. Such work certainly promises to uncover key insights into how selection leverages endocrine functioning to solve common environmental problems that animals face.

\section{Conclusions}

Our work suggests that convergent evolution of an anuran dance display is associated with similar modifications to the androgenic hormone system, specifically, increased AR expression in the thigh musculature; however, the evolutionary path of this relationship varies across taxa. These data support the hypothesis that androgenmuscle regulation provides a common conduit for selection to drive the evolution of adaptive motor command. We suspect that this occurs because hormone systems exhibit a propensity to govern specific behavioral traits, making them evolutionary paths of least resistance for phenotypic innovation.

\section{Acknowledgments}

We thank Sharmila Gowri Shankar, P. F. Gowri Shankar, and P. Prashanth of Kãlinga Center for Rainforest Ecology; Guddekere, Shivamogga, and C. Suresh of Honey Valley Estate; Yavakapady and Kodagu for field support and accommodation; and G. Ravikanth of Ashoka Trust for Research in Ecology and the Environment for lab support in India. Approval for access of biological resources in India was granted by the Research by National Biodiversity Authority (government of India) and by the principal chief conservator of forests and chief wildlife warden of the Karnataka State Forest Department. We also thank the Amazon Conservation Association and the staff at Los Amigos Biological Station for facilitating our fieldwork in Peru. Research and collecting and exporting permits for Peru were issued by the Dirección General Forestal y de Fauna Silvestre and the Servicio Nacional Forestal y de Fauna Silvestre of Peru. We thank the Vienna Zoo, staff of the Rainforest House, and A. Weissenbacher for assistance with Bornean rock frogs. We thank M. C. Miles for helping collect frogs. Finally, we thank A. R. Ives, L. Z. Garamszegi, A. P. Møller, J. J. Soler, P. T. Raimondi, S. Ramachandran, and L. J. Revell for comments and advice on our statistical approach. This work was funded by National Science Foundation grants IOS-1947472 (to M.J.F.) and OISE-1952542 (to M.J.F.).

\section{Statement of Authorship}

D.P., L.A.M., and M.J.F. conceived and planned the study; E.R.S., J.C.C.M., R.v.M., L.A.M., K.V.G., H.P., M.F.J., and D.P. collected data; J.C.C.M., R.v.M., K.V.G., and H.P. provided resources; N.K.A. and M.J.F. analyzed and interpreted data; N.K.A. and M.J.F. wrote the manuscript; all authors reviewed and edited the manuscript; and M.J.F. funded and oversaw the project.

\section{Data and Code Availability}

The data used in this study are archived at the Dryad Digital Repository (https://doi.org/10.5061/dryad.3n5tb2rhh; Anderson 2021).

\section{Literature Cited}

Abzhanov, A., W. P. Kuo, C. Hartmann, B. R. Grant, P. R. Grant, and C. J. Tabin. 2006. The calmodulin pathway and evolution of elongated beak morphology in Darwin's finches. Nature 442:563567.

Adkins-Regan, E. 2005. Hormones and animal social behavior. Monographs in Behavior and Ecology. Princeton University Press, Princeton, NJ.

- 2008. Do hormonal control systems produce evolutionary inertia? Philosophical Transactions of the Royal Society B 363: 1599-1609.

Amézquita, A., and W. Hödl. 2004. How, when, and where to perform visual displays: the case of the Amazonian frog Hyla parviceps. Herpetologica 60:420-429.

Anderson, N. K. 2021. Data from: A common endocrine signature marks convergent evolution of an elaborate dance display in frogs. American Naturalist, Dryad Digital Repository, https://doi.org/10 .5061/dryad.3n5tb2rhh.

Bass, A. H. 2008. Steroid-dependent plasticity of vocal motor systems: novel insights from teleost fish. Brain Research Reviews 57:299-308.

Bass, A. H., and L. Remage-Healey. 2008. Central pattern generators for social vocalization: androgen-dependent neurophysiological mechanisms. Hormones and Behavior 53:659-672.

Bates, D., M. Mächler, B. Bolker, and S. Walker. 2014. Fitting linear mixed-effects models using lme4. R package version 1.1-7. https://arxiv.org/abs/1406.5823.

Bauer, C. M., J. L. Graham, M. Abolins-Abols, B. J. Heidinger, E. D. Ketterson, and T. J. Greives. 2018. Chronological and biological age predict seasonal reproductive timing: an investigation of clutch initiation and telomeres in birds of known age. American Naturalist 191:777-782.

Bergeon Burns, C. M., K. A. Rosvall, and E. D. Ketterson. 2013. Neural steroid sensitivity and aggression: comparing individuals of two songbird subspecies. Journal of Evolutionary Biology 26:820 831.

Bester-Meredith, J. K., and C. A. Marler. 2001. Vasopressin and aggression in cross-fostered California mice (Peromyscus californicus) and white-footed mice (Peromyscus leucopus). Hormones and Behavior 40:51-64. 
Biju, S. D., S. Garg, K. V. Gururaja, Y. Shouche, and S. A. Walujkar. 2014. DNA barcoding reveals unprecedented diversity in dancing frogs of India (Micrixalidae, Micrixalus): a taxonomic revision with description of 14 new species. Ceylon Journal of Science 43:37-123.

Bonilla, M. M., J. A. Zeh, and D. W. Zeh. 2016. An epigenetic resolution of the lek paradox. BioEssays 38:355-366.

Brantley, R. K., M. A. Marchaterre, and A. H. Bass. 1993. Androgen effects on vocal muscle structure in a teleost fish with inter- and intra-sexual dimorphism. Journal of Morphology 216:305-318.

Bustin, S. A., V. Benes, J. A. Garson, J. Hellemans, J. Huggett, M. Kubista, R. Mueller, et al. 2009. The MIQE guidelines: minimum information for publication of quantitative real-time PCR experiments. Clinical Chemistry 55:611-622.

Canoine, V., L. Fusani, B. Schlinger, and M. Hau. 2007. Low sex steroids, high steroid receptors: increasing the sensitivity of the nonreproductive brain. Developmental Neurobiology 67:57-67.

Chakraborty, M., and S. S. Burmeister. 2010. Sexually dimorphic androgen and estrogen receptor mRNA expression in the brain of túngara frogs. Hormones and Behavior 58:619-627.

Chambon, C., D. Duteil, A. Vignaud, A. Ferry, N. Messaddeq, R. Malivindi, S. Kato, P. Chambon, and D. Metzger. 2010. Myocytic androgen receptor controls the strength but not the mass of limb muscles. Proceedings of the National Academy of Sciences of the USA 107:14327-14332.

Chen, L., A. L. Devries, and C. H. C. Cheng. 1997. Convergent evolution of antifreeze glycoproteins in Antarctic notothenioid fish and Arctic cod. Proceedings of the National Academy of Sciences of the USA 94:3817-3822.

Chenoweth, S. F., and K. McGuigan. 2010. The genetic basis of sexually selected variation. Annual Review of Ecology, Evolution, and Systematics 41:81-101.

Coddington, E. J., and A. Cree. 1995. Effect of acute captivity stress on plasma concentrations of corticosterone and sex steroids in female whistling frogs, Litoria ewingi. General and Comparative Endocrinology 100:33-38.

Corcoran, A. J., and N. I. Hristov. 2014. Convergent evolution of antibat sounds. Journal of Comparative Physiology A 200:811-821.

Cox, R. M. 2020. Sex steroids as mediators of phenotypic integration, genetic correlations, and evolutionary transitions. Molecular and Cellular Endocrinology 502:110668.

David, P., T. Bjorksten, K. Fowler, and A. Pomiankowski. 2000. Condition-dependent signalling of genetic variation in stalk-eyed flies. Nature 406:186-188.

Denver, R. J. 1999. Evolution of the corticotropin-releasing hormone signaling system and its role in stress-induced phenotypic plasticity. Annals of the New York Academy of Sciences 897:46-53.

Endler, J. A. 1986. Natural selection in the wild. Princeton University Press, Princeton, NJ.

Erulkar, S. D., and R. W. Soller. 1980. Interactions among lumbar motoneurons on opposite sides of the frog spinal cord: morphological and electrophysiological studies. Journal of Comparative Neurology 192:473-488.

Felice, R. N., and A. Goswami. 2018. Developmental origins of mosaic evolution in the avian cranium. Proceedings of the National Academy of Sciences of the USA 115:555-560.

Felsenstein, J. 1985. Phylogenies and the comparative method. American Naturalist 125:1-15.

Feng, N. Y., A. Katz, L. B. Day, J. Barske, and B. A. Schlinger. 2010. Limb muscles are androgen targets in an acrobatic tropical bird. Endocrinology 151:1042-1049.
Finch, C. E., and M. R. Rose. 1995. Hormones and the physiological architecture of life history evolution. Quarterly Review of Biology 70:1-52.

Fischer, E. K., J. P. Nowicki, and L. A. O'Connell. 2019. Evolution of affiliation: patterns of convergence from genomes to behaviour. Philosophical Transactions of the Royal Society B 374:20180242.

Forsyth, I. A., and M. Wallis. 2002. Growth hormone and prolactinmolecular and functional evolution. Journal of Mammary Gland Biology and Neoplasia 7:291-312.

Fry, B. G., K. Roelants, D. E. Champagne, H. Scheib, J. D. A. Tyndall, G. F. King, T. J. Nevalainen, et al. 2009. The toxicogenomic multiverse: convergent recruitment of proteins into animal venoms. Annual Review of Genomics and Human Genetics 10:483511.

Fusani, L., J. Barske, L. D. Day, M. J. Fuxjager, and B. A. Schlinger. 2014a. Physiological control of elaborate male courtship: female choice for neuromuscular systems. Neuroscience and Biobehavioral Reviews 46:534-546.

Fusani, L., Z. Donaldson, S. E. London, M. J. Fuxjager, and B. A. Schlinger. 2014b. Expression of androgen receptor in the brain of a sub-oscine bird with an elaborate courtship display. Neuroscience Letters 578:61-65.

Fuxjager, M. J., J. Eaton, W. R. Lindsay, L. H. Salwiczek, M. A. Rensel, J. Barske, L. Sorenson, L. B. Day, and B. A. Schlinger. 2015. Evolutionary patterns of adaptive acrobatics and physical performance predict expression profiles of androgen receptorbut not oestrogen receptor - in the forelimb musculature. Functional Ecology 29:1197-1208.

Fuxjager, M. J., J.-H. Lee, T.-M. Chan, J. H. Bahn, J. G. Chew, X. Xiao, and B. A. Schlinger. 2016. Hormones, genes, and athleticism: effect of androgens on the avian muscular transcriptome. Molecular Endocrinology 30:254-271.

Fuxjager, M. J., M. C. Miles, F. Goller, J. Petersen, and J. Yancey. 2017. Androgens support male acrobatic courtship behavior by enhancing muscle speed and easing the severity of its tradeoff with force. Endocrinology 158:4038-4046.

Fuxjager, M. J., and B. A. Schlinger. 2015. Perspectives on the evolution of animal dancing: a case study of manakins. Current Opinion of Behavavioral Sciences 6:7-12.

Fuxjager, M. J., J. D. Schultz, J. Barske, N. Y. Feng, L. Fusani, A. Mirzatoni, L. B. Day, M. Hau, and B. A. Schlinger. 2012. Spinal motor and sensory neurons are androgen targets in an acrobatic bird. Endocrinology 153:3780-3791.

Fuxjager, M. J., and E. R. Schuppe. 2018. Androgenic signaling systems and their role in behavioral evolution. Journal Steroid Biochemistry and Molecular Biology 184:47-56.

Gallant, J. R., and L. A. O'Connell. 2020. Studying convergent evolution to relate genotype to behavioral phenotype. Journal of Experimental Biology 223:jeb213447.

Garland, T., Jr. 1992. Rate tests for phenotypic evolution using phylogenetically independent contrasts. American Naturalist 140:509-519.

Garland, T., Jr., P. E. Midford, and A. R. Ives. 1999. An introduction to phylogenetically based statistical methods, with a new method for confidence intervals on ancestral values. American Zoologist 39:374-388.

Gebhardt, F. M., H. A. Scott, and P. R. Dodd. 2010. Housekeepers for accurate transcript expression analysis in Alzheimer's disease autopsy brain tissue. Alzheimer's and Dementia 6:465474. 
Germano, J. M., F. C. Molinia, P. J. Bishop, and A. Cree. 2009. Urinary hormone analysis assists reproductive monitoring and sex identification of bell frogs (Litoria raniformis). Theriogenology 72:663-671.

Grafe, T. U., D. Preininger, M. Sztatecsny, R. Kasah, J. M. Dehling, S. Proksch, and W. Hödl. 2012. Multimodal communication in a noisy environment: a case study of the Bornean rock frog Staurois parvus. PLoS ONE 7:e37965.

Grafe, T. U., and J. Tony. 2017. Temporal variation in acoustic and visual signalling as a function of stream background noise in the Bornean foot-flagging frog, Staurois parvus. Journal of Ecoacoustics 1:X74QE0.

Gupta, G., M. Rajalakshmi, and M. R. N. Prasad. 1974. Regional differences in androgen thresholds of the epididymis of the castrated rat. Steroids 24:575-586.

Gururaja, K. V. 2010. Novel reproductive mode in a torrent frog Micrixalus saxicola (Jerdon) from the Western Ghats, India. Zootaxa 2642:45-52.

Harrison, P. W., A. E. Wright, and J. E. Mank. 2012. The evolution of gene expression and the transcriptome-phenotype relationship. Seminars in Cellular and Developmental Biology 23:222-229.

Harvey, P. H., and M. D. Pagel. 1991. The comparative method in evolutionary biology. Vol. 239. Oxford Series in Ecology and Evolution. Oxford University Press, Oxford.

Hau, M. 2007. Regulation of male traits by testosterone: implications for the evolution of vertebrate life histories. BioEssays 29:133-144.

Heyduk, K., J. J. Moreno-Villena, I. S. Gilman, P. A. Christin, and E. J. Edwards. 2019. The genetics of convergent evolution: insights from plant photosynthesis. Nature Reviews Genetics 20:485-493.

Heyland, A., J. Hodin, and A. M. Reitzel. 2005. Hormone signaling in evolution and development: a non-model system approaches. BioEssays 27:64-75.

Ho, L. S. T., C. Ane, R. Lachlan, K. Tarpinian, R. Feldman, Q. Yu, W. Van Der Bijl, M. Lam, and S. T. Ho. 2018. phylolm: phylogenetic linear regression. https://CRAN.R-project.org/package $=$ phylolm .

Hödl, W., and A. Amézquita. 2001. Visual signaling in anuran amphibians. Pages 121-141 in M. J. Ryan, ed. Anuran communication. Smithsonian Institution, Washington, DC

Holmes, M. M., C. L. Bartrem, and J. Wade. 2007. Androgen dependent seasonal changes in muscle fiber type in the dewlap neuromuscular system of green anoles. Physiology and Behavior 91:601-608.

Hosken, D. J., and P. Stockley. 2004. Sexual selection and genital evolution. Trends in Ecology and Evolution 19:87-93.

Insel, T. R., Z. X. Wang, and C. F. Ferris. 1994. Patterns of brain vasopressin receptor distribution associated with social organization in microtine rodents. Journal of Neuroscience 14:53815392.

Jemiolo, B., and S. Trappe. 2004. Single muscle fiber gene expression in human skeletal muscle: validation of internal control with exercise. Biochemical and Biophysical Research Communications 320:1043-1050.

Johnson, G., A. A. Nour, T. Nolan, J. Huggett, and S. Bustin. 2014. Minimum information necessary for quantitative real-time PCR experiments. Methods in Molecular Biology 1160:4-17.

Johnson, M. A., B. K. Kircher, and D. J. Castro. 2018. The evolution of androgen receptor expression and behavior in Anolis lizard forelimb muscles. Journal of Comparative Physiology A 204:71-79.
Johnston, S. E., J. Gratten, C. Berenos, J. G. Pilkington, T. H. Clutton-Brock, J. M. Pemberton, and J. Slate. 2013. Life history trade-offs at a single locus maintain sexually selected genetic variation. Nature 502:93-95.

Ketterson, E. D., J. W. Atwell, and J. W. McGlothlin. 2009. Phenotypic integration and independence: hormones, performance, and response to environmental change. Integrative and Comparative Biology 49:365-379.

King, J. A., and R. P. Millar. 1995. Evolutionary aspects of gonadotropin-releasing hormone and its receptor. Cellular and Molecular Neurobiology 15:5-23.

Kolbe, J. J., L. J. Revell, B. Szekely, E. D. Brodie III, and J. B. Losos. 2011. Convergent evolution of phenotypic integration and its alignment with morphological diversification in Caribbean Anolis ecomorphs. Evolution 65:3608-3624.

Lai, Y. T., C. K. L. Yeung, K. E. Omland, E. L. Pang, Y. Hao, B. Y. Liao, H. F. Cao, et al. 2019. Standing genetic variation as the predominant source for adaptation of a songbird. Proceedings of the National Academy of Sciences of the USA 116:2152-2157.

Li, Y., Z. Liu, P. Shi, and J. Zhang. 2010. The hearing gene Prestin unites echolocating bats and whales. Current Biology 20:R55-R56.

Liu, Y., J. A. Cotton, B. Shen, X. Han, S. J. Rossiter, and S. Zhang. 2010. Convergent sequence evolution between echolocating bats and dolphins. Current Biology 20:R53-R54.

Losos, J. B. 1992. The evolution of convergent structure in Caribbean Anolis communities. Systematic Biology 41:403-420.

2011. Convergence, adaptation, and constraint. Evolution 65:1827-1840

Mahler, D. L., T. Ingram, L. J. Revell, and J. B. Losos. 2013. Exceptional convergence on the macroevolutionary landscape in island lizard radiations. Science 341:292-295.

Mahoney, D. J., K. Carey, M.-H. Fu, R. Snow, D. Cameron-Smith, G. Parise, and M. A. Tarnopolsky. 2004. Real-time RT-PCR analysis of housekeeping genes in human skeletal muscle following acute exercise. Physiological Genomics 18:226-231.

Manceau, M., V. S. Domingues, R. Mallarino, and H. E. Hoekstra. 2011. The developmental role of Agouti in color pattern evolution. Science 331:1062-1065.

Mangiamele, L. A., and M. J. Fuxjager. 2018. Insight into the neuroendocrine basis of signal evolution: a case study in footflagging frogs. Journal of Comparative Physiology A 204:6170 .

Mangiamele, L. A., M. J. Fuxjager, E. R. Schuppe, R. S. Taylor, W. Hödl, and D. Preininger. 2016. Increased androgenic sensitivity in the hind limb muscular system marks the evolution of a derived gestural display. Proceedings of the National Academy of Sciences of the USA 113:5664-5669.

McGlothlin, J. W., D. J. Whittaker, S. E. Schrock, N. M. Gerlach, J. M. Jawor, E. A. Snajdr, and E. D. Ketterson. 2010. Natural selection on testosterone production in a wild songbird population. American Naturalist 175:687-701.

Michel, G., and E.-E. Baulieu. 1980. Androgen receptor in rat skeletal muscle: characterization and physiological variations. Endocrinology 107:2088-2098.

Moen, D. S., H. Morlon, and J. J. Wiens. 2016. Testing convergence versus history: convergence dominates phenotypic evolution for over 150 million years in frogs. Systematic Biology 65:146160.

Morris, S. C. 2003. Life's solution: inevitable humans in a lonely universe. Cambridge University Press, Cambridge. 
2008. The deep structure of biology: is convergence sufficiently ubiquitous to give a directional signal. Templeton Foundation, West Conshohocken, PA.

Narayan, E. J., F. C. Molinia, K. S. Christi, C. G. Morley, and J. F. Cockrem. 2010. Annual cycles of urinary reproductive steroid concentrations in wild and captive endangered Fijian ground frogs (Platymantis vitiana). General Comparative Endocrinology 166:172-179.

Nogawa-Kosaka, N., T. Hirose, N. Kosaka, Y. Aizawa, K. Nagasawa, N. Uehara, H. Miyazaki, N. Komatsu, and T. Kato. 2010. Structural and biological properties of erythropoietin in Xenopus laevis. Experimental Hematology 38:363-372.

Nolan, T., R. E. Hands, and S. A. Bustin. 2006. Quantification of mRNA using real-time RT-PCR. Nature Protocols 1:1559-1582.

Nowicki, J. P., M. S. Pratchett, S. P. W. Walker, D. J. Coker, and L. A. O'Connell. 2020. Gene expression correlates of social evolution in coral reef butterflyfishes. Proceedings of the Royal Society B 287:20200239.

Numan, M., and L. J. Young. 2016. Neural mechanisms of motherinfant bonding and pair bonding: similarities, differences, and broader implications. Hormones and Behavior 77:98-112.

Oldfield, R. G., and H. A. Hofmann. 2011. Neuropeptide regulation of social behavior in a monogamous cichlid fish. Physiology and Behavior 102:296-303.

Olofsson, J. K., L. T. Dunning, M. R. Lundgren, H. J. Barton, J. Thompson, N. Cuff, M. Ariyarathne, et al. 2019. Populationspecific selection on standing variation generated by lateral gene transfers in a grass. Current Biology 29:3921-3927.

Ord, T. J., J. A. Stamps, and J. B. Losos. 2013. Convergent evolution in the territorial communication of a classic adaptive radiation: Caribbean Anolis lizards. Animal Behavior 85:1415-1426.

Pagel, M. 1999. Inferring the historical patterns of biological evolution. Nature 401:877-884.

Paradis, E., J. Claude, and K. Strimmer. 2004. APE: analyses of phylogenetics and evolution in R language. Bioinformatics 20:289290.

Park, J. W., M. Hecker, M. B. Murphy, P. D. Jones, K. R. Solomon, G. Van Der Kraak, J. A. Carr, et al. 2006. Development and optimization of a Q-RT PCR method to quantify CYP19 mRNA expression in testis of male adult Xenopus laevis: comparisons with aromatase enzyme activity. Comparative Biochemistry and Physiology B 144:18-28.

Partha, R., B. K. Chauhan, Z. Ferreira, J. D. Robinson, K. Lathrop, K. K. Nischal, M. Chikina, and N. L. Clark. 2017. Subterranean mammals show convergent regression in ocular genes and enhancers, along with adaptation to tunneling. eLife 6:e25884.

Pascoal, S., T. Cezard, A. Eik-Nes, K. Gharbi, J. Majewska, E. Payne, M. G. Ritchie, M. Zuk, and N. W. Bailey. 2014. Rapid convergent evolution in wild crickets. Current Biology 24:1369-1374.

Pedersen, A., and M. L. Tomaszycki. 2012. Oxytocin antagonist treatments alter the formation of pair relationships in zebra finches of both sexes. Hormones and Behavior 62:113-119.

Pfaffl, M. W. 2001. A new mathematical model for relative quantification in real-time RT-PCR. Nucleic Acids Research 29:e45.

Pomiankowski, A., and A. P. Moller. 1995. A resolution of the lek paradox. Proceedings of the Royal Society B 260:21-29.

Preininger, D., M. Boeckle, and W. Hödl. 2009. Communication in noisy environments. II. Visual signaling behavior of male footflagging frogs Staurois latopalmatus. Herpetologica 65:166173 .
Preininger, D., M. Boeckle, and M. Sztatecsny. 2013. Divergent receiver responses to components of multimodal signals in two foot-flagging frog species. PLoS ONE 8:55367.

Prezeworski, M., G. Coop, and J. D. Wall. 2005. The signature of positive selection on standing genetic variation. Evolution 59:23122323.

Přikryl, T., P. Aerts, P. Havelková, A. Herrel, and Z. Roček. 2009. Pelvic and thigh musculature in frogs (Anura) and origin of anuran jumping locomotion. Journal of Anatomy 214:100-139.

Pyron, R. A., and J. J. Wiens. 2011. A large-scale phylogeny of Amphibia including over 2800 species, and a revised classification of extant frogs, salamanders, and caecilians. Molecular Phylogenetics and Evolution 61:543-583.

Rand, M. N., and S. M. Breedlove. 1995. Androgen alters the dendritic arbors of SNB motoneurons by acting upon their target muscles. Journal of Neuroscience 15:4408-4416.

Rebeiz, M., J. E. Pool, V. A. Kassner, C. F. Aquadro, and S. B. Carroll. 2009. Stepwise modification of a modular enhancer underlies adaptation in a Drosophila population. Science 326:1663-1667.

Regnier, M., and A. A. Herrera. 1993a. Changes in contractile properties by androgen hormones in sexually dimorphic muscles of male frogs (Xenopus laevis). Journal of Physiology 461:565-581.

. 1993b. Differential sensitivity to androgens within a sexually dimorphic muscle of male frogs (Xenopus laevis). Journal of Neurobiology 24:1215-1228.

Revell, L. J. 2010. Phylogenetic signal and linear regression on species data. Methods in Ecology and Evolution 1:319-329.

- 2012. phytools: an R package for phylogenetic comparative biology (and other things). Methods in Ecology and Evolution 3:217-223.

Rodríguez, R. L., and M. D. Greenfield. 2003. Genetic variance and phenotypic plasticity in a component of female mate choice in an ultrasonic moth. Evolution 57:1304-1313.

Roelants, K., J. Jiang, and F. Bossuyt. 2004. Endemic ranid (Amphibia: Anura) genera in southern mountain ranges of the Indian subcontinent represent ancient frog lineages: evidence from molecular data. Molecular Phylogenetics and Evolution 31:730-740.

Rosvall, K. A., C. M. Bergeon Burns, J. Barske, J. L. Goodson, B. A. Schlinger, D. R. Sengelaub, and E. D. Ketterson. 2012. Neural sensitivity to sex steroids predicts individual differences in aggression: implications for behavioural evolution. Proceedings of the Royal Society B 279:3547-3555.

Ryan, M. J., and A. Keddy-Hector. 1992. Directional patterns of female mate choice and the role of sensory biases. American Naturalist 139:4-35.

Sassoon, D. A., G. E. Gray, and D. B. Kelley. 1987. Androgen regulation of muscle fiber type in the sexually dimorphic larynx of Xenopus laevis. Journal of Neuroscience 7:3198-3206.

Scheele, D., A. Wille, K. M. Kendrick, B. Stoffel-Wagner, B. Becker, O. Güntürkün, W. Maier, and R. Hurlemann. 2013. Oxytocin enhances brain reward system responses in men viewing the face of their female partner. Proceedings of the National Academy of Sciences of the USA 110:20308-20313.

Schlinger, B. A., K. Paul, and D. A. Monks. 2018. Muscle, a conduit to brain for hormonal control of behavior. Hormones and Behavior 105:58-65.

Schluter, D. 1996. Adaptive radiation along genetic lines of least resistance. Evolution 50:1766-1774.

- 2000. The ecology of adaptive radiation. Oxford University Press, Oxford. 
Schuppe, E. R., and M. J. Fuxjager. 2019. Phenotypic variation reveals sites of evolutionary constraint in the androgenic signaling pathway. Hormones and Behavior 115:104538.

Schuppe, E. R., M. C. Miles, and M. J. Fuxjager. 2020. Evolution of the androgen receptor: perspectives from human health to dancing birds. Molecular and Cellular Endocrinology 499:110577.

Schuppe, E. R., D. S. Pradhan, K. Thonkulpitak, C. Drilling, M. Black, and M. S. Grober. 2017. Sex differences in neuromuscular androgen receptor expression and sociosexual behavior in a sex changing fish. PLoS ONE 12:e0177711.

Sikkink, K. L., R. Hostager, M. E. Kobiela, N. Fremling, K. Johnston, A. Zambre, and E. C. Snell-Rood. 2020. Tolerance of novel toxins through generalized mechanisms: simulating gradual host shifts of butterflies. American Naturalist 195:485-503.

Stassen, Q. E. M., F. M. Riemers, H. Reijmerink, P. A. J. Leegwater, and L. C. Penning. 2015. Reference genes for reverse transcription quantitative PCR in canine brain tissue. BMC Research Notes 8:761.

Steiner, C. C., H. Römpler, L. M. Boettger, T. Schöneberg, and H. E Hoekstra. 2009. The genetic basis of phenotypic convergence in beach mice: similar pigment patterns but different genes. Molecular and Biological Evolution 26:35-45.

Stewart, C. B., J. W. Schilling, and A. C. Wilson. 1987. Adaptive evolution in the stomach lysozymes of foregut fermenters. Nature 330:401-404.

Swanson, B. O., T. A. Blackledge, A. P. Summers, and C. Y. Hayashi. 2006. Spider dragline silk: correlated evolution in highperformance biological materials. Evolution 60:2539-2551.

Taylor, E. B., and J. D. McPhail. 2000. Historical contingency and ecological determinism interact to prime speciation in sticklebacks, Gasterosteus. Proceedings of the Royal Society B 267:23752384.

Thompson, J. N. 2005. Coevolution: the geographic mosaic of coevolutionary arms races. Current Biology 15:R992-R994.

Tomkins, J. L., J. Radwan, J. S. Kotiaho, and T. Tregenza. 2004. Genic capture and resolving the lek paradox. Trends in Ecology and Evolution 19:323-328.

Touchberry, C. D., M. J. Wacker, S. R. Richmond, S. A. Whitman, and M. P. Godard. 2006. Age-related changes in relative expression of real-time PCR housekeeping genes in human skeletal muscle. Journal of Biomolecular Techniques 17:157-162.

Trillmich, F., and K. G. K. Trillmich. 1984. The mating systems of pinnipeds and marine iguanas: convergent evolution of polygyny. Biological Journal of the Linnean Society 21:209-216.
Trujillo, X., M. Ortiz-Mesina, T. Uribe, E. Castro, R. MontoyaPérez, Z. Urzú, A. Feria-Velasco, and M. Huerta. 2015. Capsaicin and $N$-arachidonoyl-dopamine (NADA) decrease tension by activating both cannabinoid and vanilloid receptors in fast skeletal muscle fibers of the frog. Journal of Membrane Biology 248:3138.

Tukey, J. W. 1977. Some thoughts on clinical trials, especially problems of multiplicity. Science 198:679-684.

Veney, S. L., and J. Wade. 2004. Steroid receptors in the adult zebra finch syrinx: a sex difference in androgen receptor mRNA, minimal expression of estrogen receptor $\alpha$ and aromatase. General and Comparative Endocrinology 136:192-199.

West, K., and A. Cohen. 1996. Shell microstructure of gastropods from Lake Tanganyika, Africa: adaptation, convergent evolution, and escalation. Evolution 50:672-681.

Wittkopp, P. J., B. L. Williams, J. E. Selegue, and S. B. Carroll. 2003. Drosophila pigmentation evolution: divergent genotypes underlying convergent phenotypes. Proceedings of the National Academy of Sciences of the USA 100:1808-1813.

Wyce, A., Y. Bai, S. Nagpal, and C. C. Thompson. 2010. Research resource: the androgen receptor modulates expression of genes with critical roles in muscle development and function. Molecular Endocrinology 24:1665-1674.

Yokoyama, S., and F. B. Radlwimmer. 2001. The molecular genetics and evolution of red and green color vision in vertebrates. Genetics 158:1697-1710.

Young, L. J. 1999. Oxytocin and vasopressin receptors and speciestypical social behaviors. Hormones and Behavior 36:212-221.

Young, R. L., M. H. Ferkin, N. F. Ockendon-Powell, V. N. Orr, S. M. Phelps, Á. Pogány, C. L. Richards-Zawacki, et al. 2019. Conserved transcriptomic profiles underpin monogamy across vertebrates. Proceedings of the National Academy of Sciences of the USA 116:1331-1336.

Zhang, Z., D. Xu, L. Wang, J. Hao, J. Wang, X. Zhou, W. Wang, et al. 2016. Convergent evolution of rumen microbiomes in highaltitude mammals. Current Biology 26:1873-1879.

Zornik, E., and D. B. Kelley. 2011. A neuroendocrine basis for the hierarchical control of frog courtship vocalizations. Frontiers in Neuroendocrinology 32:353-366.

Associate Editor: David C. Collar Editor: Russell Bonduriansky 